\title{
Metabolic host responses to infection by intracellular bacterial pathogens
}

\author{
Wolfgang Eisenreich ${ }^{1}$, Jürgen Heesemann ${ }^{2}$, Thomas Rudel $^{3}$ and Werner Goebel ${ }^{2 *}$ \\ ${ }^{1}$ Lehrstuhl für Biochemie, Center of Isotopologue Profiling, Technische Universität München, Garching, Germany \\ ${ }^{2}$ Max von Pettenkofer-Institut für Hygiene und Medizinische Mikrobiologie, Ludwig-Maximilians-Universität München, München, Germany \\ ${ }^{3}$ Lehrstuhl für Mikrobiologie, Biozentrum Universität Würzburg, Würzburg, Germany
}

\section{Edited by:}

Alain Charbit, University Paris

Descartes, France

Reviewed by:

Alain Charbit, University Paris

Descartes, France

Jaiyanth Daniel, University of

Central Florida, USA

\section{*Correspondence:}

Werner Goebel, Max von

Pettenkofer-Institut für Hygiene und

Medizinische Mikrobiologie,

Ludwig-Maximilians-Universität

München, Pettenkoferstraße 9a,

D-80336 München, Germany

e-mail: goebel@biozentrum.

uni-wuerzburg.de
The interaction of bacterial pathogens with mammalian hosts leads to a variety of physiological responses of the interacting partners aimed at an adaptation to the new situation. These responses include multiple metabolic changes in the affected host cells which are most obvious when the pathogen replicates within host cells as in case of intracellular bacterial pathogens. While the pathogen tries to deprive nutrients from the host cell, the host cell in return takes various metabolic countermeasures against the nutrient theft. During this conflicting interaction, the pathogen triggers metabolic host cell responses by means of common cell envelope components and specific virulence-associated factors. These host reactions generally promote replication of the pathogen. There is growing evidence that pathogen-specific factors may interfere in different ways with the complex regulatory network that controls the carbon and nitrogen metabolism of mammalian cells. The host cell defense answers include general metabolic reactions, like the generation of oxygen- and/or nitrogen-reactive species, and more specific measures aimed to prevent access to essential nutrients for the respective pathogen. Accurate results on metabolic host cell responses are often hampered by the use of cancer cell lines that already exhibit various de-regulated reactions in the primary carbon metabolism. Hence, there is an urgent need for cellular models that more closely reflect the in vivo infection conditions. The exact knowledge of the metabolic host cell responses may provide new interesting concepts for antibacterial therapies.

Keywords: metabolism of mammalian cells, regulation of metabolic pathways, cancer cells, intracellular bacteria, common ("core") and specific metabolic host responses, virulence-associated factors, antibacterial therapy

\section{INTRODUCTION}

Interactions between eukaryotic organisms and prokaryotes are ubiquitous. These encounters may affect the metabolism of the interacting partners in different ways, resulting in beneficial, neutral, or detrimental outcome for the partners. Highly stable metabolic win-win adaptations are manifested in the endosymbiotic interactions taking place between many invertebrates (especially protists and insects) and different bacteria (reviewed by Chaston and Goodrich-Blair, 2010). Long-lasting beneficial (or at least neutral) metabolic adaptations also occur between mammalians and their different microbiota, e.g., the microbiota of the gastrointestinal tract. However, these latter beneficial adaptations are less stable than the former ones and are often disturbed by external factors, for example by infections with bacterial pathogens (Lupp et al., 2007; Stecher et al., 2007). Metabolic adaptations occurring in eukaryotic hosts upon acute infection by bacterial pathogens are ultimately always conflicting, as the host tries to eliminate the invading pathogen while the pathogen tries to profit from host nutrients and other metabolites to satisfy its bioenergetic and biosynthetic requirements thereby damaging the host. Frequent metabolic changes may therefore occur on the part of the pathogen and on the part of the host in the course of an infection. The elucidation of metabolic host responses to bacterial infections - the topic of this review-is of great importance for the understanding of bacterial pathogenesis. Our present knowledge on this aspect is, however, still rather fragmentary.

Many studies have been carried out in the past to elucidate the responses of different hosts to bacterial infections mainly by transcriptomic and proteomic approaches. The main focus of most of these investigations has been placed on the pathogen-triggered immune responses, inflammation processes, endosomal vesicle formation, and trafficking (especially for intracellular pathogens), host cell survival, apoptosis, and autophagy (for reviews, see for example: Manger and Relman, 2000; Jenner and Young, 2005; Tran Van Nhieu and Arbibe, 2009), while the impact of the bacterial infections on the metabolism of the affected hosts has been rather set aside.

Yet, most of the more extensively studied cell responses, in particular cell transformation, inflammation, and specific immune response, are linked to carbon, nitrogen, and/or energy metabolism by shared enzymes, signaling pathways, and/or transcriptional regulators (Hsu and Sabatini, 2008; Mathis and Shoelson, 2011; Andersen and Kornbluth, 2013; O'Neill and Hardie, 2013). 
To a considerable extent, the missing in-depth knowledge of metabolic host responses to bacterial infections is due to the fact that the elucidation of the metabolic changes in the host and the bacterial pathogen during infections poses major experimental challenges in terms of the infection models and the analytical methods (discussed in some detail in the text below). Metabolism is a complex phenomenon that comprises multiple steps from gene to mRNA to the active enzyme. In general, message levels cannot be equated with enzyme protein levels nor can enzyme protein levels be equated with enzyme activity as documented in many instances. Metabolic flux is - as elaborated especially by Westerhoff and colleagues (e.g., van Eunen et al., 2011)—subject to "hierarchical regulation" involving changes in enzyme levels, and to "metabolic regulation" including modulations of the activity of pre-existing enzymes.

At present, analysis of metabolic host responses to bacterial pathogens is probably best accessible for the interactions between mammalian cells and intracellular bacterial pathogens, since the infected host cell represents a fairly well-defined metabolic entity.

Intracellular bacterial pathogens may in principle interfere with host metabolism by means of their common cell envelope structures [especially peptidoglycans (PG), lipopolysaccharides (LPS), lipoteichoic acids (LTA), respectively] and specific virulence-associated factors. This interference may occur on all levels, i.e., regulation and expression of nutrient sensors and transporters or regulators involved in the expression of key enzymes essential for catabolism, anabolism, and energy supply as well as in the modulation of activity of these enzymes (for a schematic overview, see Figure 1).

The mammalian hosts (mainly discussed here) possess a variety of differentiated cells with different overall metabolic activity and differently regulated metabolic pathways. The metabolic activity of these "normal" cells is often low but can be activated by various external stimuli, including microbial components (O'Neill and Hardie, 2013). This is in contrast to most cancer cells (often used as model host cells for the study of intracellular bacteria). In these cells some catabolic and anabolic pathways are always highly up-regulated, while aerobic respiration is strongly reduced even in the presence of oxygen, a metabolic state termed "Warburg-effect" or "aerobic glycolysis" (Hsu and Sabatini, 2008). Metabolic responses to intracellular bacteria may therefore vary considerably depending on the infected host cell type.

Recently, we reviewed the metabolic adaptations of some important (mainly intracellular) human pathogenic bacteria during intracellular growth (Eisenreich et al., 2010; Fuchs et al., 2012). In the current review, we will focus on the metabolic responses of the host cells to these intracellular bacterial pathogens. For a better understanding of the complex problem, we present in the first part of this review a condensed overview on the major metabolic pathways, nutrient transporters, receptors and regulators controlling the metabolism in mammalian cells (for more details of this aspect, see also Supplementary Material S1-S6), as these metabolic cell processes are potential host cell targets for the interaction with components of the bacterial pathogens.
In the second part, we discuss common and pathogen-specific changes in the host metabolism that are triggered by bacterial pathogens. The focus will be on studies with human and mammalian model hosts or host cells, but insights deriving from alternative infection models (e.g., Dictyostelium discoideum) will be included when relevant metabolic data are available.

The interference especially of intracellular bacteria with the phosphoinositide metabolism of host cells which plays a pivotal role in the regulation of receptor-mediated signal transduction, actin remodeling and membrane dynamics of eukaryotic cells will not be included in this review as this topic has been extensively reviewed in the past (Pizarro-Cerdá and Cossart, 2004; Hilbi, 2006; Weber et al., 2009).

\section{MAJOR METABOLIC PATHWAYS AND NUTRIENT TRANSPORTERS OF MAMMALIAN CELLS CATABOLIC, ANABOLIC, AND ANAPLEROTIC PATHWAYS}

Glucose and glutamine are the major carbon and/or nitrogen sources for mammalian cells (for reviews, see e.g., Wise et al., 2008; Levine and Puzio-Kuter, 2010). In addition, other carbohydrates and amino acids as well as fatty acids can serve as efficient carbon and/or energy sources. Oxidative degradation of these nutrients occurs via the conserved catabolic pathways [glycolysis $(\mathrm{GL})$, pentose-phosphate pathway (PPP), and the tricarboxylate cycle (TCA)], which are compartmentalized in part to the cytosol and in part to the mitochondria (Figure 2; for more details, see Supplementary Material S1).

Most of the low molecular nutrients, i.e., monomeric carbohydrates, amino acids, fatty acids, and nucleotides, needed for the biosynthesis of proteins, polysaccharides, lipids, and nucleic acids, respectively, are imported from the environment by a large number of membrane-bound transporters (see below). However, if necessary, these cells are also capable of synthesizing the (so-called non-essential) amino acids, fatty acids, purine and pyrimidine nucleotides as well as porphyrines via well-known, highly conserved anabolic pathways. Glucose and other carbohydrates can be synthesized by gluconeogenesis (GN), when nutrition is supported by alternative carbon sources, like glucogenic amino acids, lactate, and glycerol. The essential reactions for GN [from pyruvate via oxaloacetate (OXA) to glucose], are-in addition to the reversible enzymatic GL steps- the reactions catalyzed by pyruvate carboxylase (PC), phosphoenolpyuvate (PEP) carboxykinase (PCK), fructose-1,6-bisphosphatase (FBP), and glucose-6-phosphatase (GP) leading to OXA, $\mathrm{PEP}$, fructose-6-phosphate (F6P), and glucose, respectively (Figure 2).

In contrast to these anabolic pathways, which can occur in most cells, those leading to hormones and bile acids are specific for vertebrates. Synthesis of steroid hormones and bile acids branches-off from the common steroid (cholesterol) biosynthesis pathway, while synthesis of eicosanoid hormones branchesoff from the arachidonic acid pathway. The biosynthesis of these compounds requires several cytochrome P450-dependent hydroxylation steps, and the involvement of numerous members of the cytochrome P450 family (encoded by the CYP genes). Both classes of hormones participate also_-among others-in the regulation of metabolism. 


\section{A}

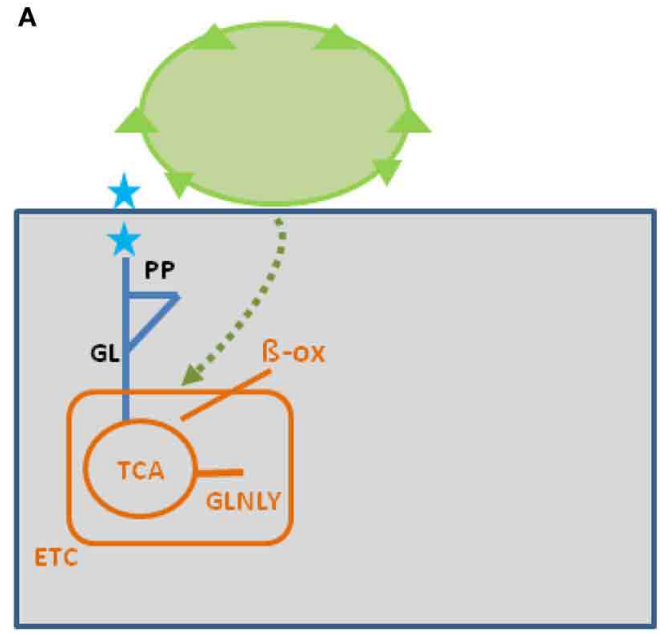

c

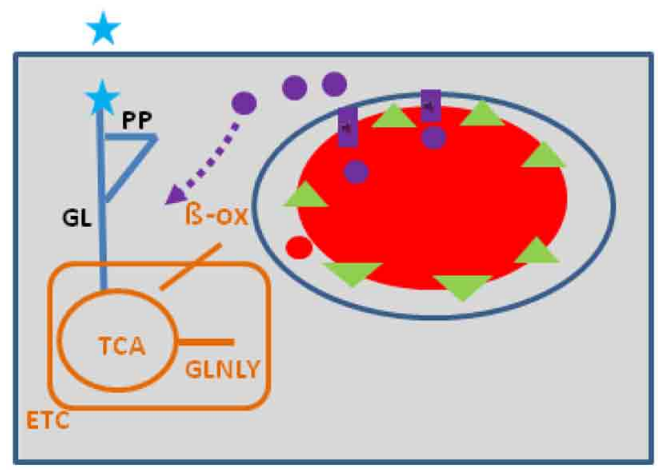

FIGURE 1 | Model showing possible interactions of common bacterial surface components and pathogen-specific virulence factors with the host cell metabolism in the cytosol (blue lines) and in the mitochondria (orange). The schematic view of the host cell (gray box) metabolism comprises glucose uptake (blue star), glycolysis (GL), pentose-phosphate shunt (PP), tricarboxylic acid cycle (TCA), glutaminolysis (GLNLY), $\beta$-oxidation of fatty acids ( $\beta$-ox), and the electron transport chain (ETC) essential for aerobic respiration. (A) Interaction with non-pathogenic bacteria (green sphere) which may trigger common metabolic host cell responses (green dashed arrows; see text for definition) mainly via cell envelope structures (e.g., PG, LPS, LTA—green triangles). (B) Extracellular bacterial pathogens

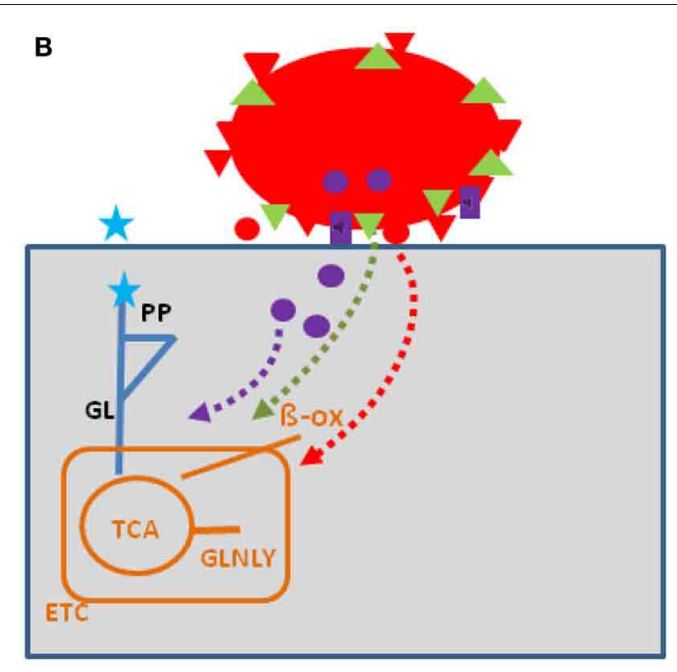

D

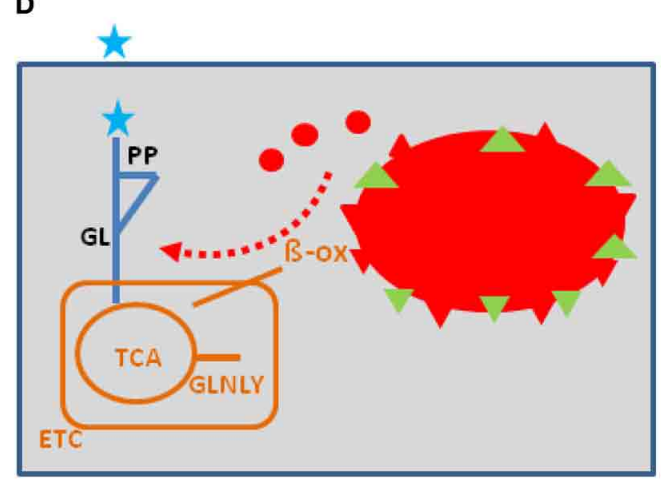

(red sphere) may trigger in addition to these common responses (green dashed arrows), specific metabolic host cell responses via cell-bound or secreted virulence factors (red triangles and red circles), as well as via specific secretion systems (e.g., T3SS or T4SS; purple boxes) translocated effector proteins (purple circles). (C) Intracellular bacterial pathogens replicating in membrane-surrounded vacuoles within the host cell could trigger metabolic host responses via translocated effector proteins (purple circles). (D) Intracellular bacterial pathogens replicating in the host cell's cytosol could trigger metabolic host responses via secreted or cell-bound virulence factors (red triangles and circles). For abbreviations and further details, see text.
Withdrawal of the TCA intermediates for biosynthetic purposes may lead to the breakdown of the TCA cycle, unless the cycle is replenished in particular by the end products of amino acid catabolic pathways or by specific refilling ("anaplerotic") reactions (see also Supplementary Material S2).

Glutaminolysis (Figure 2) is an important anaplerotic pathway for refilling the TCA cycle, especially in many cancer cells (Wise et al., 2008). Another major anaplerotic reaction is the generation of OXA catalyzed by the mitochondrial ATP-dependent PC that may be especially relevant during suppression of glutamine metabolism (Cheng et al., 2011).

\section{NUTRIENT TRANSPORTERS AND NUTRIENT SENSORS}

Most nutrients are channeled into eukayotic cells by solute carrier (SLC) transporters. The human solute-carrier gene (SLC) superfamily comprises a large number (at least 362) of putatively functional, protein-coding genes that can be divided into 55 gene subfamilies encoding membrane-bound transporters. They represent passive transporters, symporters, and antiporters, located in all cellular and organelle membranes (possibly except the nuclear membrane). Transported substrates include glucose and other sugars, amino acids and oligopeptides, nucleosides, acetyl coenzyme A, vitamins, fatty acids and lipids, essential metal ions, and other inorganic cations or anions. SLC transporters for the major nutrients may be targets for bacterial pathogens (Lee et al., 2009). Transporter-like sensors ("transceptors") may be linked to general signaling pathways, such as the protein kinase A (PKA) pathway (Hyde et al., 2003; Holsbeeks et al., 2004). For further details on the elaborate topic of nutrient transporters and nutrient sensors, the reader is 


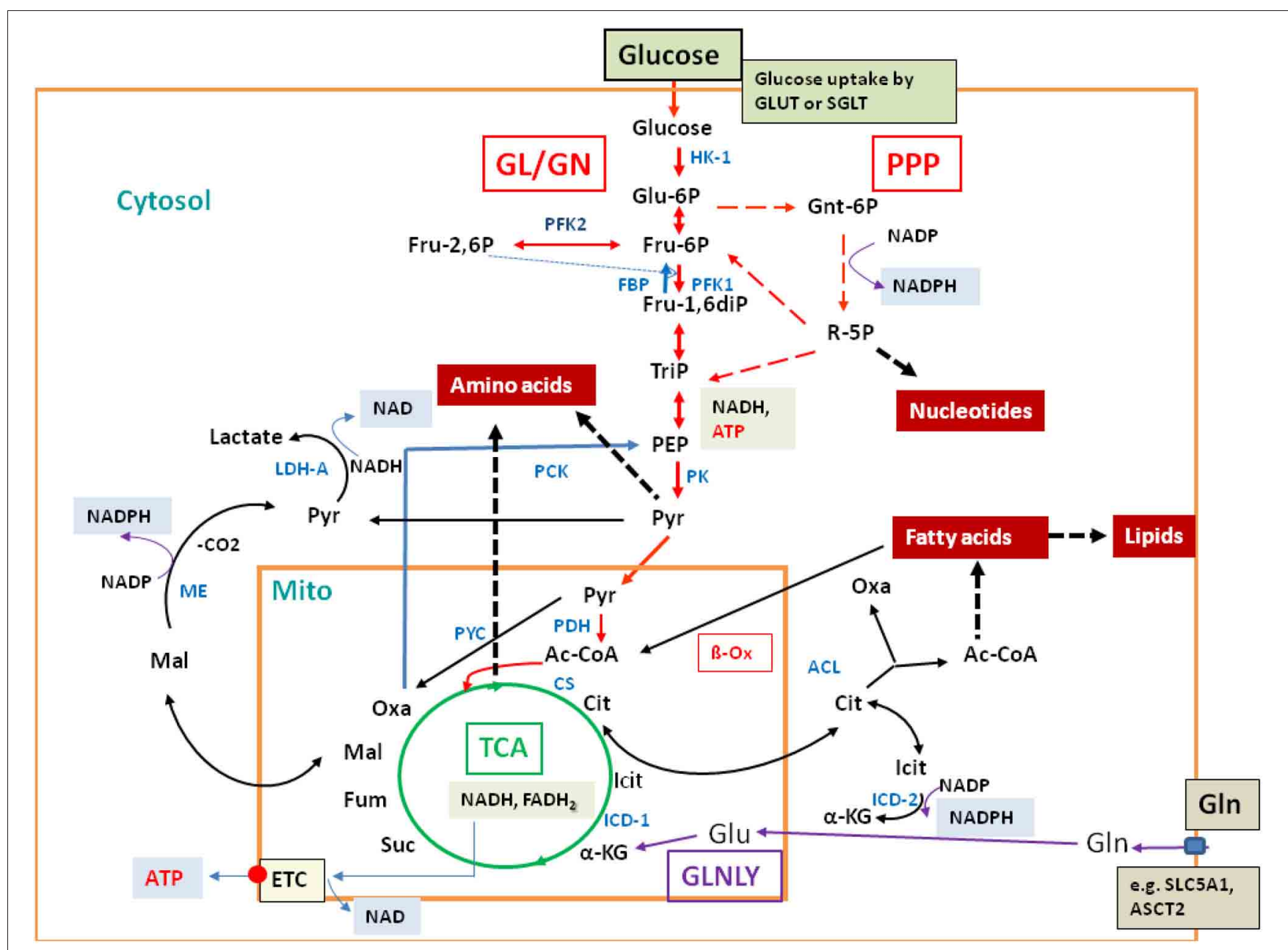

FIGURE 2 | Major catabolic and anabolic pathways in mammalian cells. Glucose uptake by the transporters GLUT or SGLT, glycolysis (GL, red arrows) and gluconeogenesis (GN; specific reactions marked by blue arrows); pentose-phosphate pathway (PPP; broken red arrows); tricarboxylic acid cycle (TCA; green circle); glutaminolysis (GLNLY, magenta arrows) and the associated TCA reactions. $\beta$-oxidation $(\beta-O x)$ and other catabolic reactions occurring in the mitochondrium and (mainly) in the cytosol are marked by black arrows. Anabolic reactions leading to amino acids, nucleotides, and lipids are indicated by broken thick black arrows. Also indicated are the reactions leading to $\mathrm{NADH}, \mathrm{NADPH}, \mathrm{NAD}$, and ATP, respectively. Metabolites are marked in black and enzymes in blue. Abbreviations: HK, hexokinase; PFK, phosphofructokinase; FBP, fructose bisphosphatase; PK, pyruvate kinase; PDH, pyruvate dehydrogenase complex; PYC, pyruvate carboxylase; PCK, PEP-carboxylase; LDH, lactate dehydrogenase; CS, citrate synthase; $I C D$, isocitrate dehydrogenase; $A C L, A T P$-dependent citrate lyase; $M E$, malate enzyme; ETC, electron transfer chain for aerobic respiration (small red circle), consisting of complexes I-IV and of ATPase (complex V); small blue box: glutamine transporters SLC1A5 and ASCT2. referred to Supplementary Material S3, S4 and the specific reviews cited there.

\section{METABOLIC REACTIONS GENERATING ANTIMICROBIAL AGENTS (ROS AND RNI) AND REACTIONS BALANCING THE CELL-TOXIC EFFECTS OF THESE AGENTS}

Mammalian cells [especially professional phagocytes, i.e., monocytes, macrophages, neutrophils, and dendritic cells (DC)] defend themselves against microbial infections not only by specific immune processes, but also by different metabolic reactions as part of the innate immunity. These reactions, mainly catalyzed by the phagocytic NADPH oxidase (PHOX) and the inducible nitric oxide synthase (iNOS or NOS2), respectively, generate reactive oxygen species (ROS) and reactive nitrogen intermediates (RNI), respectively (Bogdan et al., 2000; Nathan and Shiloh, 2000). More details on these enzymes and the regulation of their activity are provided in the Supplementary Material S5.

\section{THE ROLE OF AUTOPHAGY IN METABOLISM}

Autophagy is a highly conserved and tightly regulated catabolic process which provides basic metabolites and maintains metabolic homeostasis in cells by degrading long-lived or damaged proteins and organelles (Klionsky, 2007; Rabinowitz and White, 2010). Autophagy is induced by a variety of extraand intracellular stress stimuli, including nutrient starvation. This dynamic process includes membrane formation and fusion, leading to autophagosome formation, autophagosome-lysosome fusion, and subsequently to breakdown of the autophagosomal 
contents (which contains many cytoplasmic components) by lysosomal hydrolases. Thus, autophagy is in principle a protective mechanism that sustains cell survival under adverse conditions. Besides maintaining nutrient homeostasis, it is important as defense against intracellular pathogens.

\section{REGULATION OF METABOLIC REACTIONS IN MAMMALIAN CELLS}

Uptake and metabolism of carbohydrates (especially glucose), fatty acids, and amino acids (especially glutamine) are controlled by external signals, including hormonal and growth factors [e.g., insulin, glucagon, insulin-like growth factor (IGF), epidermal growth factor (EGF)], external nutrients (e.g., amino acids), and by numerous transcriptional factors (Figure 3). Interestingly, many of the latter factors have been first recognized as tumor suppressors or oncogenes and, hence, their role in cell cycle control, apoptosis, mitochondrial functions, etc., has been extensively studied in the past (but is not discussed here).

In the presence of external glucose, its uptake and flux through the initial reactions of GL are stimulated by the PI3K/AKT pathway. Mitogens and growth factors bind to the growth factor receptors, activate the associated tyrosine kinase which subsequently activates phosphoinositide 3 (PIP3)-kinase (PI3K). PI3K activates protein kinase B (AKT) (Mosca et al., 2011). In particular, PI3K/AKT stimulates expression of the glucose transporter 1 (GLUT1), hexokinase (HK-1), and phosphofructokinase (PFK-1). PI3K/AKT inhibits fatty acid $\beta$-oxidation $(\beta-\mathrm{Ox})$. PI3K also activates the protooncogene c-Myc (MYC) (Dang, 2010) which stimulates glucose uptake, but inhibits flux through the late steps of GL. This provides early glycolytic intermediates for

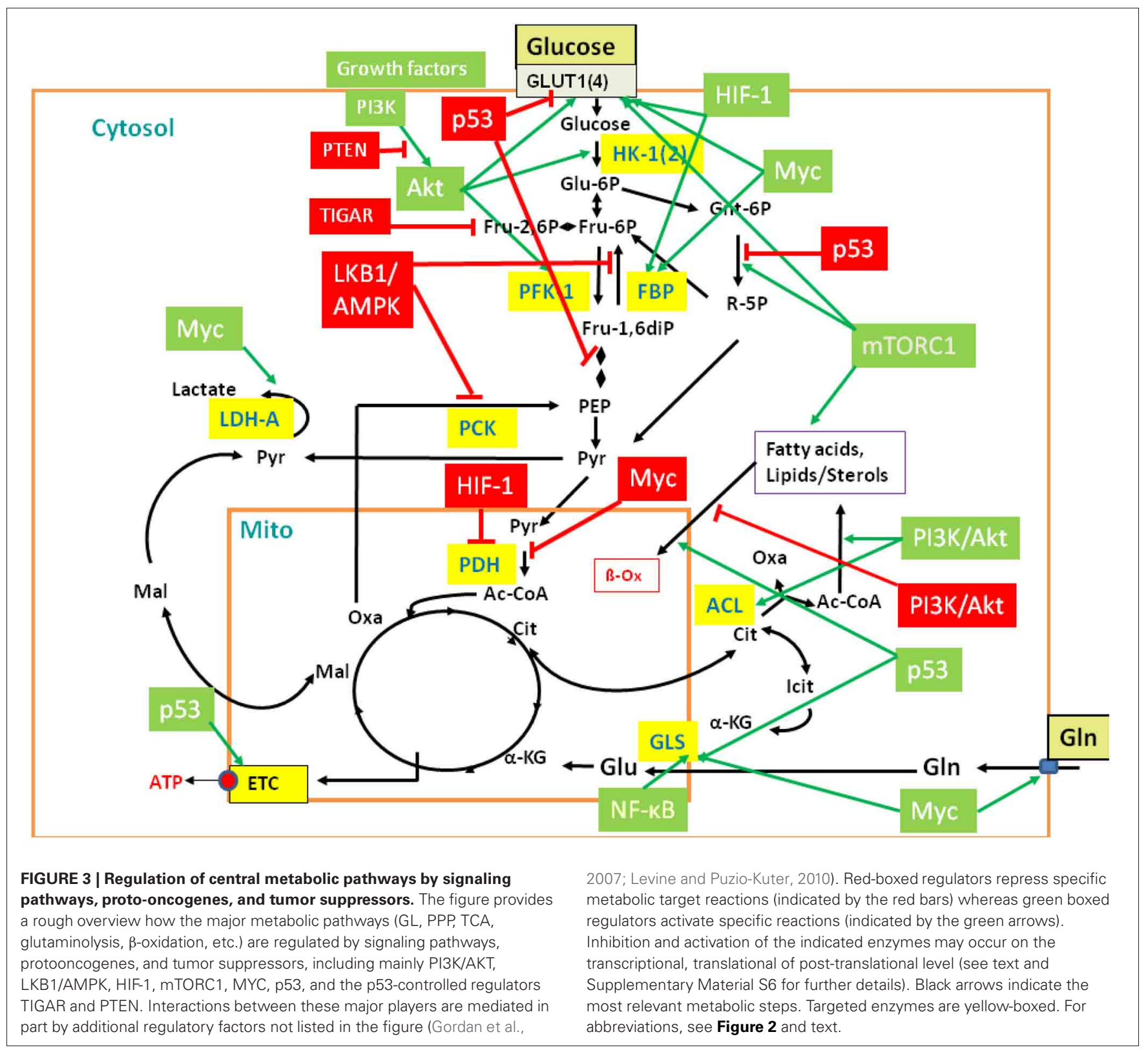


anabolic pathways and supports NADPH production. In addition, activated MYC drives glutamine metabolism. The tumor suppressor p53 (Cheung and Vousden, 2010) inhibits glucose uptake and GL (see below). However, activated AKT phosphorylates Mdm2, the key regulator of p53 stability. Activated Mdm2 ubiquitinates p53 which promotes p53 degradation and thereby stimulates GL. Furthermore, the activated PI3K/AKT pathway enhances translation of the HIF- $1 \alpha$ subunit of the hypoxia inducible transcription factor 1 (HIF-1) (Hellwig-Bürgel et al., 2005). This transcription factor also stimulates expression of genes encoding glucose transporters (especially GLUT1), several glycolytic enzymes and lactate dehydrogenase (LDH-A).

On the other hand, signaling through the serine-threonine liver kinase1/AMP-activated protein kinase (LKB1/AMPK) (Shackelford and Shaw, 2009; Hardie, 2011) decreases metabolic flux through GL in response to cell stress. Under low cellular energy conditions (high AMP/ATP ratio), AMPK triggers GL if sufficient external glucose is provided. This results in decreased AMP and glucose levels. Under low glucose condition, sustained activity of AMPK activates p53 which intervenes at several points in GL and oxidative phosphorylation and, in general, slows down GL and promotes oxidative phosphorylation. GL is inhibited by p53-induced repression of the genes for GLUT1, GLUT4, and phosphoglycerate mutase (PGM), while oxidative phosphorylation is enhanced by the increased expression of cytochrome oxidase 2 (SCO2). P53 also induces expression of the "TP53-induced GL and apoptosis regulator" (TIGAR) (Bensaad et al., 2006) and of the "tumor suppressor phosphatase and tensin homolog deleted on chromosome 10" (PTEN) (Liu and Feng, 2012). TIGAR inhibits the glycolytic flux by lowering the fructose-2,6-bisphosphate levels and inhibits expression of the glucose transporters GLUT1 and GLUT4. PTEN blocks PI3K/AKT signaling by dephosphorylation of PIP3. P53 further up-regulates transcription of the SESN gene and the produced sestrin proteins stimulate AMPK, eliciting a positive feedback loop. Another p53-activated metabolic target gene is GLS2 which encodes glutaminase 2. This enzyme converts glutamine to glutamate which may enhance the rate of the TCA pathway and oxidative phosphorylation.

AMPK, p53, and AKT converge directly or indirectly on the mammalian target of rapamycin complex 1 (mTORC1) (Dunlop and Tee, 2009). Activated AKT suppresses the tuberous sclerosis complex 2 (TSC2), an inhibitor of mTORC1, thus leading to cell growth while low AKT levels repress growth. On the other hand, activated AMPK stimulates TSC2 leading to inhibition of mTORC1 and hence to reduced cell growth. Figure 3 provides a rough overview of the discussed major players of this complex regulatory network and their metabolic targets.

Translational control elements, e.g., microRNAs (miRNAs), also participate in the regulatory network (Turner, 2000; Klip, 2009; Gao et al., 2009; Vousden and Ryan, 2009; Glatz et al., 2010; Liu et al., 2012; Chen et al., 2012). In addition, metabolic fluxes and regulation of nutrient homeostasis (especially glucose and amino acids) are controlled by post-translational modifications of metabolic enzymes and regulators (mainly by phosphorylation and acetylation) (Xiong and Guan, 2012) and by sharing of metabolic intermediates. Autophagy may also play an important role in regulation of nutrient homeostasis under nutrient starvation conditions by providing essential products for the metabolism. For more details on the regulation of the mammalian cell metabolism, see also Supplementary Material S6.

\section{METHODOLOGICAL PROBLEMS RELATED TO THE ANALYSIS OF METABOLIC HOST CELL RESPONSES TRIGGERED BY BACTERIAL PATHOGENS}

The significance of infections by bacterial pathogens on the metabolism of the infected host was early recognized (Beisel, 1975, 1984; Richards, 1980). However, conclusions regarding defined changes within the metabolic network of the infected host can hardly be drawn from these studies. The introduction of the high throughput techniques ("omics") and other modern physical methods made the metabolic aspect of bacterial pathogenesis better accessible. However, as already mentioned above, most of the numerous transcriptome studies on host responses to bacterial infections (for reviews, see Boldrick et al., 2002; Nau et al., 2002; Jenner and Young, 2005; Tam et al., 2008) provide only little information on metabolic changes triggered by the bacterial pathogens in the infected hosts or host cells. In addition, such changes depend to a large extent on post-transcriptional mechanisms, i.e., turnover processes, modulations of enzymatic activities and signaling pathways (e.g., by phosphorylation/dephosphorylation), which are hardly recognized by conventional transcriptome analyses. Application of proteomics for the analysis of metabolic host (cell) responses to bacterial infections-probably better suited for detecting such changes - is still relatively rare. More recently, metabolomics analyzing qualitatively and quantitatively small metabolites in cells or tissue samples of the infected host by MS or NMR have been also applied to determine changes in the metabolite patterns (Han et al., 2008; de Carvalho et al., 2010; Antunes et al., 2011). Other techniques which may provide valuable information on the dynamics of metabolic changes in infected host cells include ${ }^{13} \mathrm{C}$-isotopologue profiling, Raman spectroscopy, nano SIMS, and fluorescence lifetime imaging (FLIM) (Wagner, 2009; Szaszák et al., 2011; Gillmaier et al., 2012; Musat et al., 2012). Each of these methods has, however, specific drawbacks and only the integration of these techniques may provide a satisfactory solution to this complex problem (Zhang et al., 2010).

Another challenging problem is the choice of "host cells" and "animal models" used in such studies. Many investigations of host cell responses apply established mammalian cell lines, deriving from neoplastic (or artificially transformed) epithelial, fibroblastic, endothelial, or hematopoietic cells. Most differentiated cells perform in the non-activated state a balanced carbon flux through GL, PPP, and the TCA cycle, and oxidative phosphorylation is the main route to generate ATP (Figure 4A). In contrast, most cancer cells use-even in the presence of oxygenthe glycolytic pathway for ATP production, a process known as "aerobic glycolysis" or "Warburg effect" (Warburg, 1956). The initial part of the TCA cycle and oxidative phosphorylation are repressed in these cells. The enhanced GL is accompanied by an increase of glucose uptake and production of metabolic intermediates, needed for increased biomass (nucleic acids, lipids, 

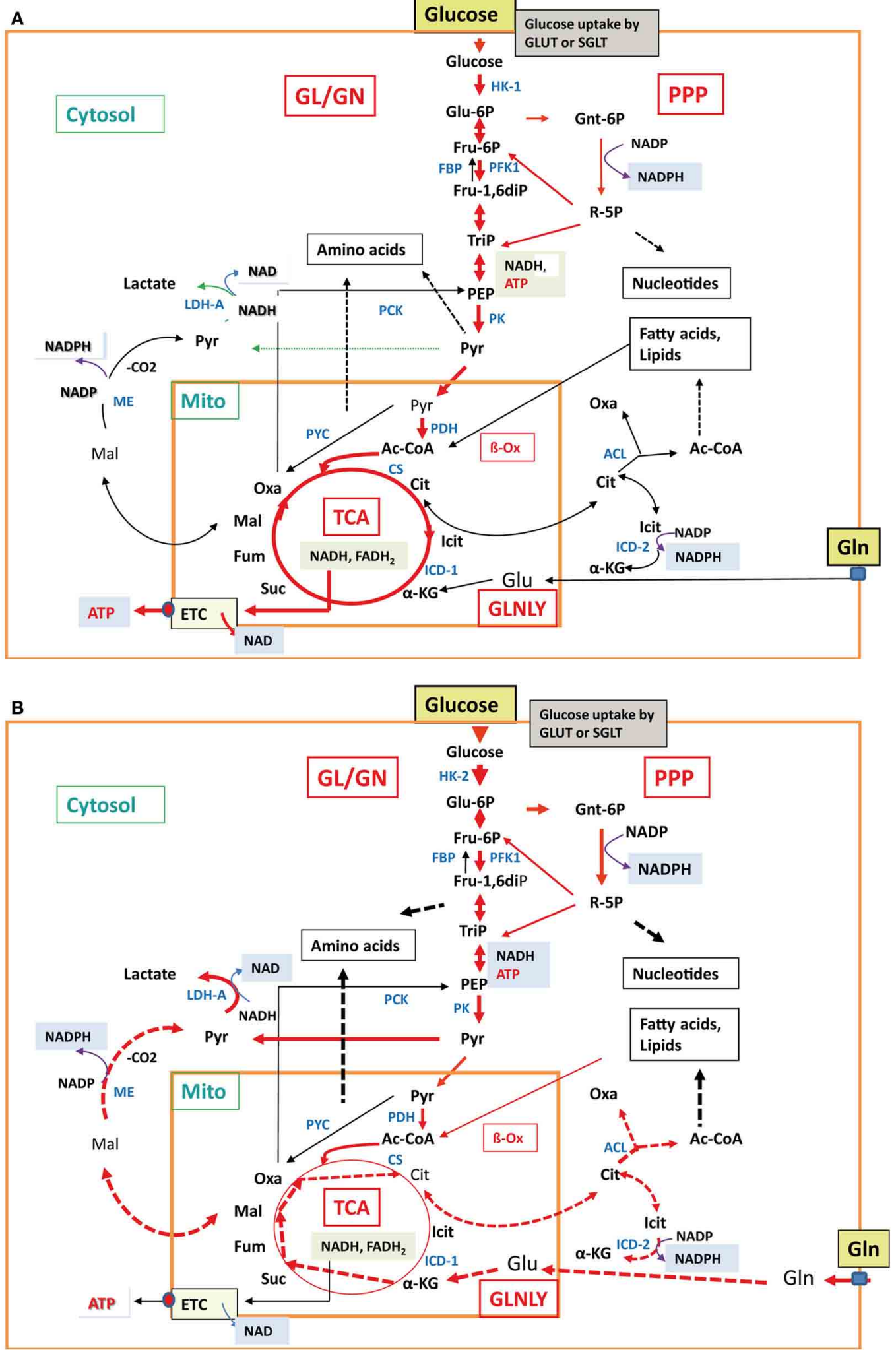

FIGURE 4 | Major metabolic pathways in normal differentiated cells and cancer cells. In normal differentiated mammalian cells (A), e.g., epithelial cell or non-activated macrophages, glucose uptake, glycolysis, TCA cycle, and aerobic respiration (indicated by the thick red arrows) are active at low balanced levels. All other less- or non-active catabolic and anabolic pathways are indicated by thin black and broken black arrows, respectively. In mammalian cancer cells (B), carbon metabolism is characterized by

(Continued) 


\section{FIGURE 4 | Continued}

enhanced glucose uptake, glycolysis, pentose-phosphate shunt, enhanced conversion of pyruvate to lactate (indicated by the thick red arrows) and reduced conversion to acetyl-CoA by pyruvate dehydrogenase, reduced TCA cycle, gluconeogenesis, and aerobic respiration (indicated by the thin red and black arrows). In some cancer cells, glutaminolysis is also highly induced with the subsequent reactions leading to $\alpha$-ketoglutarate $(\alpha-K G)$ and malate (Mal) which is converted to pyruvate by the cytosolic malic enzyme (ME) and to citrate (Cit). Cit is transported into the cytosol and converted by ATP-dependent citrate lyase to oxaloacetate (Oxa) and acetyl-CoA (Ac-CoA). These reactions are marked by the thick broken red arrows. Also induced are the anabolic reactions leading to amino acids, nucleotides, and fatty acids/lipids (indicated by the broken thick black arrows). The non-activated metabolic reactions are marked by thin black arrows. For abbreviations, see Figure 2. proteins), characteristic for cancer cells. In addition, enhanced glutaminolysis observed in many cancer cells provides necessary TCA intermediates (Figure 4B). Furthermore, these cells, but also primary macrophages (bone marrow- or blood-derived) used in infection studies, are normally cultured in rich media, containing high levels of glucose, amino acids (especially glutamine) and growth factors. Thus, many cellular nutrient transporters, central pathways involved in carbon and nitrogen metabolism and regulators controlling these processes will be already activated or suppressed (Wise et al., 2008; Levine and Puzio-Kuter, 2010). These metabolic conditions are quite different to those of primary cells encountered by the bacterial pathogens as host cells in in vivo infections (Chen and Russo, 2012). Therefore, essential metabolic pathways activated by certain bacterial pathogens in primary cells may not be further activated or even inhibited in cancer cells (or otherwise metabolically activated host cells) by the same pathogens.

The use of protists and invertebrates as infection models may pose another problem for unraveling metabolic host (cell) responses, since metabolic processes of these cells may differ from those of mammalian cells in some aspects, e.g., lack of components of the regulatory network of carbon and nitrogen metabolism. Hence, metabolic responses in these alternative infection models may be quite different from those observed in infected mammalian cells.

\section{COMMON AND SPECIFIC METABOLIC HOST REACTIONS TRIGGERED BY BACTERIAL PATHOGENS (GENERAL CONSIDERATIONS)}

Many bacteria (pathogenic and non-pathogenic) trigger metabolic host responses that are primarily directed toward inhibition of survival and proliferation of the bacteria. As shown by numerous transcriptome studies (carried out in established mammalian cell lines, primary phagocytes, or different animal infection models), many of these metabolic responses are unspecific, i.e., they occur with most extracellular and intracellular bacterial pathogens and even with non-pathogenic or killed bacteria and are therefore termed "core host responses" (Boldrick et al., 2002). PHOX generating ROS and the iNOS generating RNI belong to these general metabolic strategies (manifested especially in phagocytic cells), aimed at defending the host against bacteria (Lowenstein and Padalko, 2004; Fang, 2011). Numerous "core response genes" are regulated by NF- $\kappa$ B (Nau et al., 2002). NF-кB is activated (especially in phagocytic cells, an important host cell type in the interaction with bacteria) predominantly by bacterial pathogen-associated molecular patterns (PAMPs, representing mainly common cell envelope components, flagella, CpG DNA motifs, dsRNA) via different Toll-like or NOD-like receptors (TLR or NLR) (Shaw et al., 2008; Kawai and Akira, 2011). Several of the known PAMP-induced NF- $\kappa \mathrm{B}$ up-regulated genes encode also enzymes catalyzing important metabolic reactions, including: (a) heme oxygenase-1 (HO-1) which generates carbon monoxide (CO) from heme and thereby protects endothelial cells (EC) from tumor necrosis factor alpha (TNF- $\alpha$ )-mediated apoptosis (Brouard et al., 2002), (b) transporters for $\mathrm{Ca}^{2+}$ and other divalent metal ions (ATP2B1; NRAMP2) and for L-amino acids (SLC7A5), (c) adenosine- and adenosine-monophosphate deaminases (ADA, AMPD3), and (d) indolamine-2,3-dioxygenase (IDO).

Furthermore, NF- $\kappa \mathrm{B}$ is also involved in control of energy homeostasis and metabolic adaptations by upregulating mitochondrial respiration (Mauro et al., 2011) and glutamine metabolism by decreasing miR-23a expression (Rathore et al., 2012) in a similar manner as Myc. This miRNA represses translation of the mRNA for glutaminase (GLS). In addition, NF- $\kappa$ B seems to participate in the control GLS activity (Erickson and Cerione, 2010).

Major NF- $\kappa$ B down-regulated "metabolic core genes" encode (a) the nucleoside transporter (SLC29A1), (b) enzymes further metabolizing TCA intermediates, like the cytosolic isocitrate dehydrogenase (IDH2) and malic enzyme (ME1), (c) glycogen phosphorylase (PYGL), and (d) the catalytic subunit of glutamate/cysteine ligase (GLCLC) involved in glutathione biosynthesis.

Further common "metabolic" genes are involved in (chole)sterol homeostasis, including the up-regulated gene HSD11B1 and the down-regulated gene HSD17B4. Another apparently general host response to bacterial pathogens is the activation of the transcription factor HIF-1 by stabilization of the HIF- $1 \alpha$ subunit through hypoxic conditions caused by infections or pathogen-induced signaling (Rupp et al., 2007; Werth et al., 2010). As described above, HIF-1 controls the transcription of a large number of genes, including genes whose products are involved in glucose uptake and GL.

Together, the metabolic host cell responses triggered by bacterial pathogens that are determined by the "core response genes" aim primarily at increasing antimicrobial activities and decreasing metabolic reactions that may provide essential nutrients to the pathogens, thus inhibiting their proliferation (termed "nutriprive mechanisms") (Appelberg, 2006).

However, bacterial pathogens may also trigger infectionpromoting metabolic host responses that counteract these latter antimicrobial reactions of the host and provide protection and/or increased nutrient supply to the pathogen. These latter 
host reactions, that are still poorly investigated so far, seem to be induced mainly by pathogen-specific factors. Such metabolic host responses are expected to be different for extracellular and intracellular bacterial pathogens. Extracellular pathogens may influence the host cell metabolism mainly by cell-associated or secreted toxins, adhesins, and exoenzymes or by effector proteins that are translocated into host cells especially via type III or IV secretion systems (e.g., in Yersinia spp., enteropathogenic and enterohemorrhagic E. coli, Pseudomonas aeruginosa). These bacterial compounds may interact with different host cell targets, e.g., components of signaling pathways or transcription factors (e.g., PI3K/AKT; see Figure 3) controlling directly or indirectly host cell metabolism (for reviews see Aktories and Barbieri, 2005; Baldwin and Barbieri, 2005; Aktories, 2011; Dean, 2011).

Intracellular bacterial pathogens may influence (similar to extracellular pathogens) host cell activities prior to invasion already from the outside (Figure 1) by cell-toxic and -adhesive components and/or by effector proteins that are again injected into host cells especially by type III or IV secretion systems (e.g., Salmonella enterica, Legionella pneumophila, Chlamydia spp; reviewed by Haenssler and Isberg, 2011). Once internalized, these bacteria interfere with the host cell metabolism directly as their proliferation depends on energy sources and metabolites that are either imported or produced by the host cells (reviewed by Eisenreich et al., 2010; Fuchs et al., 2012). The resulting metabolic adaptations of host cells to intracellular bacteria may differ in each case, depending on the specific properties of the two interacting partners. On the part of the bacteria, it is especially the specific metabolic capacities and the specific virulence factors. On the part of the host cells, it is the specific antimicrobial defense mechanisms.

Despite the high relevance of this aspect for the understanding of bacterial pathogenesis, only little information is so far available on changes in the metabolic networks of the major target host cells (e.g., DCs, macrophages, gut epithelial cells, ECs, liver cells) triggered by bacterial pathogens. Since the analysis of metabolic host responses to bacterial pathogens appears to be most advanced for the interaction between mammalian cells and intracellular bacteria, we will focus our discussion in the following on the metabolic host responses triggered by some important human intracellular bacterial pathogens in cell cultures and in in vivo infection models.

\section{METABOLIC HOST RESPONSES TO SELECTED INTRACELLULAR BACTERIAL PATHOGENS METABOLIC HOST RESPONSES TO Salmonella enterica serovar Typhimurium}

Salmonella enterica serovar Typhimurium (in the following abbreviated $S$. Typhimurium) is a leading cause of gastrointestinal infections in humans and livestock (Mead et al., 1999; Herikstad et al., 2002). In the mouse model, S. Typhimurium leads to systemic infections comparable to $S$. Typhi infections in humans (Tam et al., 2008). The pathogen triggers intestinal inflammation which enhances growth in the intestinal lumen and supports invasion of the intestinal epithelium and mucosal macrophages (Stecher et al., 2007; Santos et al., 2009). After crossing the intestinal epithelium, $S$. Typhimurium is taken up primarily by DCs. Within DCs, salmonellae survive without replication (Niedergang et al., 2000; Jantsch et al., 2003) and are transported to the mesenteric lymph node (MLN). There, they can exit and spread as free bacteria or within cells to other tissues (especially liver and spleen) of the infected mammalian hosts (Paulin et al., 2002; Pullinger et al., 2007).

\section{In vitro studies}

Numerous "omics"-studies (in particular transcriptome, but also proteome and metabolome analyses) were performed with different host cells and animal (mainly mouse) models infected with S. Typhimurium (Rosenberger et al., 2000; Detweiler et al., 2001; Handley and Miller, 2007; Karavolos et al., 2008; Wang et al., 2008; Liu et al., 2010a; Antunes et al., 2011).

Not unexpectedly, transcriptome studies on Salmonellainfected mammalian cell lines did not yield much information concerning specific metabolic host responses, i.e., no apparent differential expression of metabolic genes was reported when transcript profiling was performed with $S$. Typhimurium-infected human macrophage-like U937-1 cells (Detweiler et al., 2001). Infected murine macrophage-like RAW 264.7 cells compared to the un-infected control cells showed only up-regulation of iNOS and GLUT1, encoding NO synthase and Glut1, respectively (Rosenberger et al., 2000). In a proteomic study using RAW 264.7 cells infected with $S$. Typhimurium, increased levels of iNOS and inducible cyclooxygenase 2 (COX2; converting arachidonic acid to prostaglandin) were observed $24 \mathrm{~h}$ post-infection (Shi et al., 2009).

\section{In vivo studies}

$S$. Typhimurium-infected animal models provide more relevant data regarding metabolic host responses. A global differential gene expression study in the mouse colon mucosa during S. Typhimurium infection (Liu et al., 2010a) suggests the complete shut-off of the oxidative phosphorylation early in infection $(8 \mathrm{~h})$ and the down-regulation of genes of many metabolic pathways, mainly at later times of infection (4 days). Among those, catabolism of glucose and branched chain amino acids (Val, Leu, Ile) seem to be most significantly affected. Interestingly, several genes involved in mTOR signaling are up-regulated.

Cawthraw et al. (2011) analyzed the gene expression profiles induced by $S$. Enteritidis in wild-type $\mathrm{C} 3 \mathrm{H} / \mathrm{HeN}$ mice and more susceptible TLR4-deficient $\mathrm{C} 3 \mathrm{H} / \mathrm{HeJ}$ (and $\mathrm{BALB} / \mathrm{c}$ ) mice. In the susceptible mice, more metabolic pathways seem to be affected by the infection than in the wild-type mice, including in particular GL and GN. The response to $S$. Enteritidis in the intestine is, in general, much weaker than the in vitro response in murine rectal epithelial cells (CTM93/09 cells), suggesting a tighter control of the metabolic responses to $S$. Enteritidis in the intestine than in the isolated cells (Cawthraw et al., 2011).

An interesting study on metabolic changes in C57BL/6 mice upon S. Typhimurium infection was reported (Antunes et al., 2011) using a metabolomics approach. By measuring the altered concentration of metabolites in infected and uninfected intestine and liver, the authors showed that production of many metabolites (including carbohydrates, bile acids, steroids, and eicosanoids among others) are induced or repressed in the 
samples of the infected mice compared to the uninfected control mice. Most metabolites, derived from primary glucose metabolism (GL, GN, PPP) but also from specific pathways for other carbohydrates (fructose, mannose, galactose, starch, and sucrose), decreased in the liver but not in the intestine upon infection. Whether this finding reflects the high energy expenditure that is required to fight the infection (as suggested by the authors) or a general inhibition of the carbon metabolism in the liver as a result of the $S$. Typhimurium infection remains, however, unanswered. In contrast, a highly increased concentration of metabolites involved in the arachidonic pathway (leading to eicosanoid hormones) and the $\mathrm{C}_{21}$-steroid hormone pathway was observed, suggesting that the $S$. Typhimurium infection strongly disturbs the steroid and eicosanoid hormone metabolism of the host. Some of these hormones are known regulators of carbohydrate metabolism and of immune responses (Vinson, 2009).

As mentioned above, activation of HIF-1 due to hypoxic conditions arising in infections by human pathogens seems to be a rather general phenomenon (Werth et al., 2010), which causes increased glucose uptake and GL in most host cells infected by intracellular bacteria. However, hypoxia-independent activation of HIF- $1 \alpha$ has also been demonstrated in Peyer's patches of the mice infected by different enterobacteriaceae, including $S$. Typhimurium. The pathogen-specific siderophores (salmochelin in case of $S$. Typhimurium) seem to be responsible for this activation leading to induction of several HIF-1-dependent metabolic genes, including genes for the glycolytic enzymes, hexokinase and phosphofructokinase, as well as carbonic anhydrase, observed in Peyer's patches after orogastric S. Typhimurium infection (Hartmann et al., 2008).

$S$. Typhimurium-infected macrophages reduce the host cell's iron pool by causing iron efflux from phagosomes via induced SLC11A1 (NRAMP1) (Cellier et al., 2007; Nairz et al., 2009). Subsequently, the resulting low intracellular iron concentration triggers the expression of the highly efficient iron-uptake systems in $S$. Typhimurium. This allows the bacteria to compete successfully for the remaining iron supply thus promoting their growth within the macrophages. Moreover, strong down-regulation of the gene encoding the plasma membrane calcium-transporting ATPase (PMCA) occurs in bovine Peyer' patches early in infection (Santos et al., 2002), thus increasing the cellular calcium level which affects various metabolic processes, including enhanced mitochondrial ATP synthesis (Jouaville et al., 1999).

As described above, PHOX generating ROS and iNOS generating RNI are general metabolic strategies (manifested especially in phagocytic cells) against bacterial pathogens, including Salmonella. Silencing of these reactive agents may be therefore advantageous for the pathogen. $S$. Typhimurium is able to subvert these metabolic host defense reactions by different strategies (MacFarlane et al., 1999; Shiloh et al., 1999; Mastroeni et al., 2000). These include: (a) Reduction of the host iNOScatalyzed RNI production through induction of the arginase isoform II in the spleen of infected mice. The arginase competes with iNOS for the same substrate (arginine) and thus reduces iNOS-mediated NO production which increases the proliferation of $S$. Typhimurium in the lymphoid organs of infected mice
(Lahiri et al., 2008); (b) Induction of arginine uptake through enhanced expression of the genes encoding the cationic amino acids transporters (CAT1 and CAT2) in isolated bone marrowderived macrophages (BMDMs) and DCs, but also in liver and spleen of infected mice (Das et al., 2010). The increased arginine level may lead to an increase of NO production by iNOS and hence to reinforced antimicrobial activity. However, these host cell transporters are recruited preferentially to the Salmonellacontaining vacuole (SCV) thus channeling arginine into the SCV thereby supporting growth of $S$. Typhimurium. For this goal, S. Typhimurium induces in addition the expression of the gene coding for its own arginine transporter ArgT (Das et al., 2010); (c) Using ROS (whose production is induced during Salmonella infections due to activated host cell NADPH oxidase) for its own proliferation in the intestinal lumen. ROS trigger the formation of tetrathionate $\left(\mathrm{S}_{4} \mathrm{O}_{6}^{2-}\right)$ from thiosulphate $\left(\mathrm{S}_{2} \mathrm{O}_{3}^{2-}\right)$ enriched in the intestine. Tetrathionate (but not thiosulphate) can be used by $S$. Typhimurium as electron acceptor for efficient anaerobic respiration (Winter et al., 2010).

\section{Effector proteins as possible modifiers of host cell metabolism}

All Salmonella enterica serovars infecting warm-blooded animals express two T3SSs, encoded by SPI-1 and SPI-2, respectively, which translocate specific sets of effector proteins into the host cells cytosol (for a recent review, see Moest and Méresse, 2013). While SPI-1 effectors appear to mainly trigger internalization of Salmonella by non-professional phagocytes, the SPI-2 effectors are needed for intracellular replication. Interestingly, recent data suggest that some of these effectors may also be involved in modifying the metabolism of the infected cells.

As shown (Knodler et al., 2005), S. Typhimurium residing in the SCV translocates SopB which activates Akt. This activation occurs within minutes after invasion and lasts for several hours. The Akt activation seems to be involved in the inhibition of apoptosis of the infected host cells (Knodler et al., 2005) and is essential for Salmonella (and Mycobacterium tuberculosis) infection of epithelial cells and macrophages (Kuijl et al., 2007). As discussed above, activated Akt phosphorylates Mdm2, a key regulator of p53 stability. Activated Mdm2 ubiquitinates p53 and thus promotes 553 degradation which may in turn stimulate glucose flux via GL.

AvrA, another Salmonella T3SS-translocated effector protein (Hardt and Galán, 1997), could also be responsible-either directly or indirectly-for some of the specific Salmonellainduced metabolic host responses. As shown (Liu et al., 2010b), AvrA leads to reduction of oxidative phosphorylation and to activation of $\mathrm{mTOR}, \mathrm{NF}-\kappa \mathrm{B}$ and $\mathrm{p} 53$ in intestinal in vivo infection. The activation of p53 is caused by AvrA-mediated p53 acetylation (Wu et al., 2010). While activated p53 will inhibit GL, activated mTOR may stimulate amino acids uptake and catabolism. Thus, the AvrA-mediated activation of these regulators may again modify the carbon metabolism of Salmonella-infected host cells.

In a recent study, Lopez and collegues showed that $S$. Typhimurium strains expressing the type III effector protein SopE (encoded by a lysogenic phage present in several epidemic strains) triggers the synthesis of iNOS in the host cells 
intestine (Lopez et al., 2012). The thereby produced nitric oxide is converted to nitrate in the host cell which acts as an even better electron acceptor in anaerobic nitrate respiration than $\mathrm{S}_{4} \mathrm{O}_{6}^{2-}$ in tetrathionate respiration. Under these respiratory conditions, $S$. Typhimurium is able to use the non-fermentable carbon source ethanolamine (Thiennimitr et al., 2011), a nutrient deriving from phosphatidylethanolamine that is present in the intestine (Bertin et al., 2011). This metabolic capability generates a growth advantage for $S$. Typhimurium over the inherent anaerobic intestinal microbiota that is unable to respire ethanolamine.

Salmonella infection of murine macrophage-like cell lines (RAW264.7 and J774A.1) induces the expression of COX2 (Uchiya and Nikai, 2004; Shi et al., 2009). This induction depends on the Salmonella protein SpiC, a gene product encoded within SPI-2 and translocated into host cells by T3SS-2 (Uchiya and Nikai, 2004). COX2 encodes cyclooxygenase 2, a key enzyme involved of prostanoid synthesis which leads to an increased production of $\mathrm{PGE}_{2}$ and $\mathrm{PGI}_{2}$, two prostanoids belonging to the eicosanoid hormones.

In summary, a plethora of in vitro and in vivo studies showsalbeit with still rather fragmentary evidence-that Salmonella infection leads to numerous changes of the carbon and nitrogen metabolism in the infected host (cells), which on one hand may prolong the host cell's survival and on the other hand may support the pathogen's proliferation. These metabolic changes of the host (cells) are caused by common and specific components of the pathogen. Especially the latter host cell responses are observed in in vivo models, but hardly in established cell lines. Multiple-task effector proteins, e.g., SopB, AvrA, SopE, may also be responsible for the specific changes in host cell carbon and nitrogen metabolism, by interfering with global regulators of the host cell's metabolism, like p53 and mTOR. Clearly, further studies are necessary to fully understand the impact of Salmonella infection on the complex metabolic network of the host and to unravel which Salmonella effectors are responsible for the observed specific metabolic changes of the host cells.

\section{METABOLIC HOST RESPONSES TO Mycobacterium tuberculosis}

The facultative intracellular pathogen $M$. tuberculosis belongs to the few bacterial pathogens for which humans are the only known reservoir, although it may infect mice and even amoebae (Hagedorn et al., 2009). M. tuberculosis colonizes the lung as major target organ, causing pulmonary tuberculosis (TB). Macrophages are the primary intracellular niches to which M. tuberculosis has adapted. Within these host cells, M. tuberculosis survives and replicates in a specialized phagosomal compartment. Under certain conditions, the bacteria seem to be able to escape into the host cells cytosol (van der Wel et al., 2007). Shortly after infection, granuloma are formed comprising a core of infected macrophages, surrounded by foamy macrophages, monocytes, and multinucleated giant cells (Russell, 2007). Under immunocompromised conditions, $M$. tuberculosis may also infect other organs, causing extrapulmonary TB. The visceral adipose tissue has been proposed as an important reservoir for persistence of M. tuberculosis (Neyrolles et al., 2006).
Because of its medical importance, extensive effort has been made to understand the complex metabolism of M. tuberculosis under in vitro and in vivo conditions. This aspect is far from being completely solved (Rhee et al., 2011), but the metabolic responses of the target host cells and tissues to M. tuberculosis infections are even less understood. Numerous studies using transcript profiling were performed with infected host cells (mainly macrophages) and mice (Ehrt et al., 2001; Wang et al., 2003; Kendall et al., 2004; Volpe et al., 2006). In addition, proteomics and metabolomics studies were applied to M. tuberculosis-infected cells and animal models (Shui et al., 2009; de Carvalho et al., 2010; Somashekar et al., 2011, 2012). These studies allowed important insights into immune responses induced by $M$. tuberculosis, but also provided some clues how M. tuberculosis modulates metabolic processes of the infected host cells.

\section{In vitro studies}

Most of the observed metabolic changes in M. tuberculosisinfected host cells are again linked to defense mechanisms, including oxidative stress and production of antimicrobial peptides. Macrophages can inhibit M. tuberculosis replication by iNOSgenerated RNI (Adams et al., 1997). This enzyme is induced upon M. tuberculosis infection of macrophages (Ehrt et al., 2001). Induction of PHOX, leading to increased levels of ROS has also been reported (Wang et al., 2003; Shui et al., 2009). Yet, M. tuberculosis is relatively resistant to killing by ROS as these ROS are inactivated by the induced mycobacterial catalase KatG ( $\mathrm{Ng}$ et al., 2004) which has catalase and peroxidase activity (Heym et al., 1993). M. tuberculosis infection also stimulates expression of heme oxygenase (HO-1) in mouse macrophages and other host cells, probably via the TNF- $\alpha$ signaling pathway (Shiloh et al., 2008). CO, one of the reaction products of HO-1, together with NO generated by iNOS, seems to induce transcription of the Mtb dormancy regulon via the two-component system DosS/T (Shiloh et al., 2008). Furthermore, increased levels of host cell proteins involved in the generation of ROS, like the p67phox subunit of NADPH oxidase and the neutrophil cytosolic factor 1 (NCF1 or p47) required for activation of NADPH oxidase are observed. Finally, the production of the Mn-dependent superoxide dismutase, acting as an antioxidant (by quenching ROS and hydrogen peroxide) is up-regulated.

The unique mycobacterial cell wall lipids play an important role in M. tuberculosis pathogenesis processes (Russell et al., 2002; Korf et al., 2005). Exposure of J774A.1 macrophage-like cells to $M$. tuberculosis lipids results in a total of 166 differentially expressed macrophage proteins (Shui et al., 2009). A substantial portion of the differentially expressed proteins (14\%) seem to be involved in metabolism, but the functions of these proteins are not further elaborated.

\section{In vivo studies}

Progression of human TB leads to the development of caseous pulmonary granuloma, comprising a core of infected macrophages. Previous reports show an abundance of lipid species (mainly cholesterol, cholesterol ester, and triacylglycerol) in these cells of $M$. tuberculosis-infected mice and TB patients (Garner et al., 2002; Hunter et al., 2007). Transcriptome analysis 
of such TB granuloma reveals significant up-regulation of genes involved in sequestration, catabolism, and synthesis of host lipids (Kim et al., 2010). Many of the up-regulated genes are also induced by TNF- $\alpha$, indicating that this response may be caused by the sustained inflammation triggered mainly by $M$. tuberculosis cell wall components. The thereby accumulated lipids could serve as suitable carbon source for $M$. tuberculosis colonizing the granuloma in a dormant state.

Important information on metabolic host changes is provided by recent ${ }^{1} \mathrm{H}$-NMR-based metabolite profiling studies from the mouse and guinea pig M. tuberculosis infection models (Shin et al., 2011; Somashekar et al., 2011). The infected mice show qualitatively similar changes of major catabolic and anabolic metabolites in all tissues tested (lung, liver, and spleen). Quantitatively, the most significant effects are observed in the lung, the major target of M. tuberculosis infection. The levels of glucose and glycogen as well as those of NAD and NADP decrease, while lactate concentration increases, suggesting increased consumption of glucose via GL and the pentose-phosphate shunt. The decreased level of the TCA cycle intermediates OXA and fumarate, suggesting reduced activity of the TCA cycle, supports this assumption. Yet, the level of succinate, another TCA cycle intermediate increases. This elevated amount of succinate may be generated by enhanced glutaminolysis in mitochondria induced by the oxidative stress occurring during $M$. tuberculosis infection (see above) (Fedotcheva et al., 2006). Alternatively, succinate may be secreted by M. tuberculosis. As shown (Muñoz-Elías and McKinney, 2005), bacterial production of succinate could increase due to the induction of the glyoxylate and methylcitrate cycles caused by switching the $M$. tuberculosis carbon metabolism toward $\beta$-oxidation of fatty acids due to the enhanced lipolysis in the host cells. Interestingly, the amount of many amino acids also increases in the analyzed tissues and even in serum of the M. tuberculosis-infected mice, suggesting enhanced proteolysis and/or catabolism of ingested amino acids. This metabolic change might be related to the "anabolic block" observed in TB patients (Macallan et al., 1998).

Furthermore, increased amounts of several intermediates of pyrimidine and purine nucleotide biosynthesis are observed in the lung which is taken as evidence that cells in the M. tuberculosis-infected lung actively divide (Shin et al., 2011). An increased level of the antioxidant glutathione (GSH) is also observed in the infected lung (and spleen) and probably represents an additional metabolic defense reaction against the induced oxidative stress. Metabolite profiling of the lung tissues and serum of infected guinea pigs (Somashekar et al., 2011) reveal similar patterns of metabolites as in the infected mice, also suggesting enhanced GL, glutaminolysis and GN triggered by the M. tuberculosis infection.

In summary, M. tuberculosis infection causes strong metabolic host responses concerning host defense against the infection, but also enhanced lipid metabolism, glucose consumption, and proteolysis. These metabolic host responses, observed again mainly in the in vivo (mouse and guinea pig) models, seem to support intracellular replication of $M$. tuberculosis. The unique mycobacterial cell wall components apparently play a major role in most of the observed metabolic host responses.

\section{METABOLIC HOST RESPONSE TO Listeria monocytogenes}

The Gram-positive facultative intracellular bacterium L. monocytogenes is the only species of the genus Listeria that is pathogenic for humans, whereas the other members are either pathogenic only to animals (L. ivanovii) or are harmless saprophytes living mainly in natural environments. Clinical symptoms of L. monocytogenes infections range from febrile gastroenteritis to encephalomeningitis, sepsis, and abortion. L. monocytogenes escapes from the phagosome and replicates primarily in the host cells cytosol, but replication in so-called spacious Listeriacontaining phagosomes (SLAPs) may also occur (Birmingham et al., 2008). The latter mode of intracellular listerial replication is dependent on the recruitment of the autophagy protein LC3 to the phagosome and low production of listeriolysin (LLO). The mechanism of action of this and the other virulence factors of L. monocytogenes has been extensively studied on the molecular level using appropriate cellular and animal model systems (for recent reviews, see Camejo et al., 2011; Stavru et al., 2011). The expression of most of these virulence factors is induced within the infected host cells (reviewed by de las Heras et al., 2011).

\section{In vitro studies}

Genes involved in metabolism (with the exception of HIF$1 \alpha)$ are apparently not differentially expressed in the human macrophage-like cell line THP-1 upon L. monocytogenes infection (Cohen et al., 2000). This result may be in part the consequence of the incomplete gene array used in this study, but-more likely - is again due to the already upregulated metabolism of the used THP-1 cells (even in the uninfected state-see above). This assumption is supported by recent ${ }^{13} \mathrm{C}$-isotopologue studies, carried out with primary murine bone marrow-derived macrophages (BMM) and the murine macrophage-like J774A.1 cells infected with L. monocytogenes (Gillmaier et al., 2012). When the two cell types are fed with uniformly ${ }^{13} \mathrm{C}$-labeled glucose or ${ }^{13} \mathrm{C}$-labeled glutamine, high induction of glucose uptake and GL is observed in BMM upon infection with L. monocytogenes, but not in the J774A.1 cells (which already show up-regulated GL and glutaminolysis in the un-infected state). In contrast, the activity of the TCA cycle and glutaminolysis remains unaffected in the L. monocytogenes-infected BMM. The L. monocytogenesinduced carbon metabolism in BMM allows a similarly efficient proliferation of the internalized bacteria in BMM as in J774A.1 cells.

\section{In vivo studies}

In mice expressing humanized E-cadherin, the host response was analysed by transcript profiling of the intestinal epithelia after infection with a L. monocytogenes wild-type strain and compared to the response of germ-free mice and of mice infected with a non-pathogenic L. innocua strain (Lecuit et al., 2007). The supplementary part of this report provides interesting data concerning specific L. monocytogenes-induced metabolic host responses. Transcription of most GL genes is enhanced after infection, but the gene encoding hexosekinase II (HKII) shows the highest increase (about 10-fold). This suggests that glucose taken up is mostly phosphorylated by HK-II, which has easy access to ATP due to its close association to mitochondria. The product, 
glucose-6P, is an important carbon substrate for intracellular L. monocytogenes in epithelial cells and macrophages (ChicoCalero et al., 2002; Eylert et al., 2008). The enhanced glucose-6P production will be therefore advantageous for the cytosolic proliferation of L. monocytogenes. The induced expression of the GL genes and of the gene for lactate dehydrogenase may be linked to the observed enhanced HIF-1 $\alpha$ gene expression. In line with the increased expression of the GL genes is the down-regulation of the genes for fructose bisphosphatases 1 and 2 (playing a central role in GN) and of glutamate dehydrogenase (involved in glutaminolysis). Transcription of the genes encoding pyruvate dehydrogenase and citrate synthase is also increased while all other genes encoding TCA cycle enzymes and the genes involved in the electron transfer chain (ETC) are not differentially regulated. Possibly, the produced citrate is mainly transported into the cytosol and converted by ATP-dependent citrate lyase into OXA and acetyl-CoA and used for biosynthesis of aspartate and fatty acids, respectively. There is also a remarkable up-regulation of genes encoding key enzymes involved in the biosynthesis of serine (phosphoserine aminotransferase) and asparagine (asparagine synthetase). The observed metabolic host responses appear to be triggered by intracellular listeriae since a non-invasive inlA, inlB mutant does not cause up-regulation of these genes. This suggests that secreted listerial virulence factors whose synthesis is induced under intracellular conditions may modulate the metabolic host responses observed in this in vivo study and also in the above described ${ }^{13} \mathrm{C}$-isotopolog studies with L. monocytogenes-infected primary mouse macrophages. The two phospholipases $\mathrm{C}$ ( $\mathrm{PlcA}$ and $\mathrm{PlcB}$ ) and listeriolysin are potential candidates, as they were shown to interact with signaling pathways of mammalian cells (Goldfine and Wadsworth, 2002; Kayal and Charbit, 2006; Gekara et al., 2008).

Another notable result of this in vivo transcriptome analysis is the dramatic down-regulation of several CYP genes encoding members of the cytochrome P450 families which represent monooxygenases catalyzing mainly the hydroxylation of steroid and eicosanoid substrates (Marohnic et al., 2006). The CYP genes that are most strongly down-regulated in the L. monocytogenes-infected mouse intestinal epithelium encode monooxygenases involved in biosynthesis of oxysterols and bile acids (Pikuleva, 2006). In this context, recent data (Zou et al., 2011) is of interest showing that L. monocytogenes triggers the up-regulation of $\mathrm{Ch} 25 \mathrm{~h}$ in macrophages. This gene encodes cholesterol 25-hydroxylase responsible for the formation of 25hydroxycholesterol from cholesterol. Increased levels of Ch25h support survival of L. monocytogenes-infected cells (Zou et al., 2011). In accord with this assumption is the strong downregulation of CYP39A1 encoding a hydroxylase that converts cholesterol via the 24-cholesterol pathway and thus reduces the formation of 25-hydroxycholesterol.

As expected, transcriptional up-regulation of the genes encoding iNOS and IDO (indolylamine 2,3-dioxygenase) is also observed which in conjunction with the transcriptional downregulation of the genes for arginase type II (competing with iNOS for Arg) and catalase supports host defense reactions against L. monocytogenes. This finding is in accord with results of another study (Sonje et al., 2010) also showing highly increased expression of iNOS and IDO in neonatal mice upon infection with L. monocytogenes. It should be noted, however, that induced expression of these genes occurs even in TNF receptor 1 (TNFR1) knock-out mice, which are highly susceptible for L. monocytgenes infection. This indicates that increased levels of iNOS and IDO do not suffice to cause antilisterial protection and that TNF- $\alpha$ signaling is absolutely needed for protection against L. monocytogenes.

In summary, L. monocytogenes has a strong impact on the host cell metabolism, especially when internalized by mammalian host cells. Some of the virulence factors, notably LLO and the two phospholipases, may be responsible for at least some of the observed metabolic host responses. Especially the studies with L. monocytogenes-infected "humanized" mice and with primary mouse macrophages show that L. monocytogenes induces reactions of the host cell carbon metabolism that favor uptake of glucose and the production of compounds, such as glucose-6P, serine, and glycerol, which are preferably utilized by the bacteria for their own intracellular metabolism (Eylert et al., 2008). Furthermore, the internalized bacteria appear to trigger a striking change of the host cell steroid metabolism that may also support intracellular survival (e.g., by causing LLO activation, and/or reduced bile acid formation).

\section{METABOLIC HOST RESPONSE TO Chlamydia spp.}

The genus Chlamydia comprises several obligate intracellular species. Among those, C. trachomatis is the most extensively studied. In humans, C. trachomatis infects ocular and urogenital epithelial tissues and causes trachoma and sexually transmitted diseases (Byrne, 2010). All Chlamydia species exhibit a partially disrupted primary carbon metabolism and lack most anabolic pathways. Hence, intracellular chlamydiae have to take up most of the required metabolites and energy from the host cell (McClarty, 1994; Fuchs et al., 2012). Amino acids seem to be the major carbon and energy source for the impaired metabolic activities of the intracellular chlamydiae. Amino acids may be provided to the bacteria by the host cell through lysosomal degradation of external proteins (Ouellette et al., 2011). In addition, the chlamydial proteases CPAF and cHtrA are secreted into the host cells cytosol where they may degrade host proteins (Zhong et al., 2001; Wu et al., 2011; Chen et al., 2012). For sustaining a stable hostparasite interaction, the host cell has to substantially re-adjust its metabolism upon infection with chlamydiae.

\section{Studies with Chlamydia-infected host cells and tissues}

Since there are no suitable animal models for Chlamydia, all gene expression profiling studies reporting on host cell responses to chlamydial infections are performed with infected cell lines and tissues (e.g., Stephens, 2003; Alvesalo et al., 2008; Amirshahi et al., 2011). Not unexpectedly, these studies provide only little information on differentially expressed metabolic genes. In Hep-2 cells infected with C. pneumoniae, induction of host cell genes involved in glucose uptake and GL is observed, caused (at least in part) by hypoxia-mediated HIF-1 $\alpha$ stabilization (Rupp et al., 2007; Werth et al., 2010).

Host-cell derived lipids, especially sphingomyelin, are essential for intracellular growth of $C$. trachomatis and the formation of the inclusion body. Reactivation of persistent $C$. trachomatis requires 
the induced host cell sphingolipid biosynthesis (Robertson et al., 2009). The enhanced lipid biosynthesis in the host cells relies on higher NADPH consumption which may explain the preferential glucose flux through the PPP observed in C. trachomatis-infected cells (Fukuda et al., 2005; Szaszák et al., 2011).

A recent gene expression analysis in conjunctival swab samples of patients with active trachoma and healthy controls (Natividad et al., 2010) provides (mainly in the Supplementary Material part) a plethora of interesting data on differentially expressed metabolic genes that may shed light on the metabolic host responses to $C$. trachomatis infection. Of particular note is the highly up-regulated transcription of many genes encoding nutrient transporters, i.e., transporters for glucose, including members of the SLGT family (e.g., SLC5) and the GLUT family (e.g., SLC2A3, SLC2, SLC2A14, SLC2A5), for cationic, neutral, and aromatic amino acids (e.g., SLC7A11, SLC14A4, SLC16A, SLC1A4, SLC7A11), for peptides (SLC15A3), for metal ions (e.g., SLC39A8, SLC8A1, SLC24A, SLC11A1), for glycerol-3P (SLC37A) and for nucleosides (SLC38A3). Assuming a correspondingly increased translation of these transcripts, the data suggest that induction of transporters required for the uptake of nutrients essential for intracellular growth is a strong metabolic host response to a chlamydial infection. It will be interesting to find out whether these transporter proteins are incorporated into the host cell cytoplasmic membrane or recruited to the Chlamydia containing vacuole ("inclusion body"). Not surprisingly, none of these transporter genes upregulated in the tissue samples have been found differentially expressed in productively and persistently Chlamydia-infected HeLa or HL cells using transcriptomic (Eickhoff et al., 2007; Alvesalo et al., 2008) or proteomic approaches (Savijoki et al., 2008). As discussed above, nutrient uptake is already induced in these transformed cell lines. Indeed, expression of amino acid transporter genes and of other metabolic genes seems to be even down-regulated in these transformed host cells upon infection with C. pneumoniae (Alvesalo et al., 2008).

As expected, increased expression of genes encoding NADPH oxidase and iNOS is also observed in the above gene expression analysis of the patients' tissue samples. This causes enhanced production of ROS and RNI which may support the host defense against the intracellular Chlamydia. The enhanced expression of the host genes for superoxide dismutase (SOD2) and arginase II (ARG2) probably protects the host cells against the cell-damaging ROS and RNI.

In summary, the metabolic host cell responses to chlamydial infections are highlighted by increased glucose uptake and glucose flux through GL. The pentose-phosphate shunt is also induced and may be linked to the enhanced anabolic performance (increased protein and lipid synthesis) of the host cells observed during the proliferative phase of the chlamydial infection. The remarkable up-regulation of many genes encoding transporters for nutrients needed for intracellular chlamydial growth suggests increased import of these nutrients by the host cells and possible recruitment of these nutrient transporters to the membrane surrounding the Chlamydia-containing vacuole ("inclusion"). So far, nothing is known about chlamydial factors that may be responsible for the metabolic responses of the infected host cells.

\section{METABOLIC HOST RESPONSE TO Coxiella burnetii}

C. burnetii, the etiological agent of the human disease $\mathrm{Q}$ fever, belongs-like the Chlamydia spp.- - to the group of obligate intracellular human pathogens, but replicates in acidified $(\mathrm{pH} 4.5-5)$ phagolysosome-like vacuoles.

Transcriptional host response to C. burnetii infection is mainly studied in the human macrophage-like cell line THP-1 (Ren et al., 2003; Mahapatra et al., 2010). THP-1 cells, infected with C. burnetii or Chlamydia trachomatis, respectively, show an extensive overlap in up- and down-regulated genes, but pathogen-specific differential gene expression is also observed (Ren et al., 2003). Only few of the common and species-specific differentially regulated genes are involved in host cell metabolism and none in carbon metabolism which may be again due to the already activated primary carbon metabolism of the host cell line used (see above).

The common up-regulated genes include SLC2A6, encoding a facilitated transporter that can also transport glucose, TDO2, encoding tryptophan 2,3-dioxygenase which, like indoleamine 2,3 dioxygenase (IDO), catalyzes the first step in the degradation of tryptophan, $C Y B B$ (NOX2), encoding gp91, the major subunit of phagosomal NADPH oxidase, and FTH1 (encoding ferritin heavy chain) which oxidizes Fe(II) to Fe (III). In addition to the transcriptional up-regulation of FTH1, C. burnetii, unlike C. trachomatis, also induces the expression of the transferrin receptor gene $(T f R)$ in murine macrophage-like J774A.1 cells, resulting in a 2.5 -fold increase in cellular iron concentration (Howe and Mallavia, 1999). Since the metabolic activities of $C$. burnetii are strongly affected by iron in vitro, this finding suggests that the $T f R$ up-regulation is important for the iron supply during intracellular replication of $C$. burnetii. In addition, the reactions catalyzed by NOX 2 and NADP oxidase may help to protect the host cells against exceeding growth of the intracellular bacteria.

Among the host metabolic genes that are specifically upregulated by $C$. burnetii are $R E N B P$ encoding $\mathrm{N}$-acylglucosamine 2-epimerase that is involved in amino sugar and nucleotide sugar metabolism, PIR (Wendler et al., 1997) encoding the iron-binding protein and transcriptional co-factor pirin, which is involved in numerous cellular processes, and ATP6V1H encoding a subunit of the $\mathrm{V}$-ATPase, a vacuolar proton pump.

Changes in cellular lipids, especially in the cellular cholesterol level, have been observed during infections by phagosomal intracellular bacteria, including S. enterica, M. tuberculosis, and C. burnetii (Howe and Heinzen, 2006). The up-regulation of host genes involved in lipid metabolism in C. burnetii infected THP-1 cells (Ren et al., 2003; Mahapatra et al., 2010) is in line with this observation.

Although both, ROS and RNI are involved in the host defense against C. burnetii infection (Brennan et al., 2004), a hallmark in metabolic host response to $C$. burnetii is the dramatic decrease of NADPH oxidase in neutrophils (Siemsen et al., 2009) which seems to be due to the inactivation of neutrophil NADPH oxidase by phagocytosed Coxiella. A T2SS-dependent secreted acidic phosphatase of Coxiella appears to be responsible for this process (Hill and Samuel, 2011). Bacterial phosphatases could be even more generally involved in silencing the NADPH oxidase by 
intracellular bacteria, as these bacteria frequently encode secreted protein- and/or phosphoinositide-phosphatases (Tabernero et al., 2008; Kastner et al., 2011).

C. burnetii also secretes protein effectors into the cytosol via a T4SS that is similar to the Dot/Icm T4SS of Legionella pneumophila (Carey et al., 2011). As in L. pneumophila (see below), effector proteins have been described that modulate host cell functions, e.g., membrane trafficking (Voth and Heinzen, 2009), but so far no Coxiella effector has been identified that might be involved in the modulation of host cell metabolism.

In summary, the scattered information on the metabolic host response against Coxiella infection is mainly based on transcriptome data obtained from Coxiella-infected cell lines and is hence of limited significance, especially as far as the primary carbon metabolism is concerned. Major host metabolic responses seem to be the induction of iron uptake and the destruction of the NADPH oxidase caused by Coxiella infection, two reactions that favor the intracellular replication of these bacteria.

\section{METABOLIC HOST RESPONSE TO Legionella pneumophila}

L. pneumophila is the best studied member of the genus Legionella. This facultative intracellular pathogen replicates intracellularly within a specialized phagosome, the Legionellacontaining vacuole (LCV) in human alveolar macrophages and in amoebae. Acanthamoeba castelanii and the social amoeba Dictyostelium discoideum are well-established model organisms for studying the L. pneumophila intracellular life style. Virulence of L. pneumophila is most strikingly determined by the Dot/Icm T4SS, which translocates about 300 effector proteins into the host cell (Isberg et al., 2009). Some of these effectors participate in the remodeling of the primary phagosome to the LCV, essential for intracellular replication, and in the manipulation of host cell signal transduction pathways through phosphorylation/dephosphorylation reactions (for recent reviews, see Shin and Roy, 2008; Haenssler and Isberg, 2011).

An explicit participation of translocated effectors in the modulation of the host cell's metabolism has not yet been demonstrated. However, some observations argue for a direct or indirect involvement of effector proteins in metabolic processes: (a) in macrophages and in the Dictyostelium model, Dot/Icm effectors may play a critical role in autophagy with a possible consequence for host cell metabolism (Otto et al., 2004; Amer et al., 2005; Tung et al., 2010), (b) L. pneumophila-infected human macrophagelike U937 cells activate NF- $\kappa \mathrm{B}$ signaling in a Dot/Icm-dependent manner (Losick and Isberg, 2006) by the effector protein LnaB (Losick et al., 2010). NF-кB, well-known as an important regulator of cell survival and differentiation, is also linked to metabolic processes, e.g., glutamine metabolism (Rathore et al., 2012), (c) putative Dot/Icm-dependent serine/threonine protein kinases and phosphatases may modulate the activity of metabolic enzymes as well as host signaling pathways and possibly downstream metabolic processes (Chien et al., 2004; Li et al., 2009; Hervet et al., 2011).

Comprehensive transcriptome studies on host cell response to L. pneumophila infection are so far only available for L. pneumophila-infected D. discoideum (Farbrother et al., 2006). Differential expression is observed for many metabolic genes of
D. discoideum (mainly seen $24 \mathrm{~h}$ after infection) whose impact on host cell metabolism is summarized by the authors in two major conclusions: (a) enzymatic activities involved in bacterial degradation, protein biosynthesis, and fatty acid modification are down-regulated and (b) expression of genes involved in metabolic activities that ultimately generate products needed for the proliferation of the pathogen is induced. Based on the data, the authors suggest that "Legionella specifically manipulates the host by differentially regulating its metabolism, upregulating activities that produce nutrients suitable for the pathogen and downregulating the host-specific metabolism."

This rather general statement is in line with a more in depth biochemical study (Wieland et al., 2005) showing that expression of the amino acids transporter SLC1A5 (specific for neutral amino acids) is highly induced in the human monocyte cell line MM6 upon infection by L. pneumophila. This study also shows that functional SLC1A5 transporter is important for L. pneumophila proliferation in these cells and preliminary evidence suggests that SLC1A5 is translocated to the LCV membrane thus supporting the uptake of cysteine, serine, and glutamine into the LCV. These amino acids seem to be essential carbon sources for growth of intracellular L. pneumophila (Price et al., 2011). Interestingly, induction of the amino acid transporter SLC1A5 has been also reported in THP-1 cells infected by the intracellularly replicating Francisella tularensis (Barel et al., 2012).

In summary, solid experimental data on metabolic responses of the primary host cells (i.e., macrophages in human infections and amoebae in natural environments) to L. pneumophila are scarce. Clearly, in depth biochemical studies (especially using human macrophages) are needed to support the interesting, albeit mostly still preliminary findings, and to answer the important question of how L. pneumophila modulates the metabolism in its target cells. Some of the numerous Legionella effector proteins might be interesting candidates.

\section{CONCLUSIONS}

Despite the rather limited knowledge that is currently available concerning metabolic responses of mammalian cells to bacterial pathogens, some common and pathogen-specific motifs are recognizable. As expected, most of the general observed changes in host cell metabolism support cell protection and include in particular the induced expression of $i N O S, P H O X$, and IDO, leading to increased production of ROS, RNI, and tryptophan degradation products, respectively. The also frequently observed decreased expression of nucleoside transporter, isocitrate dehydrogenase, malic enzyme, and PYGL may cause reduced access to essential metabolic intermediates for the invading pathogens. Another common theme seems to be the generation of hypoxic conditions leading to HIF- $1 \alpha$ stabilization with the subsequent induction of HIF-1 dependent genes which comprise also the genes involved in glucose uptake and GL. These common metabolic host responses (denoted as "core response") are mainly triggered by bacterial PAMPs, shared by pathogenic and non-pathogenic bacteria.

However, bacterial pathogens may induce in addition specific metabolic host responses which are probably in favor of these bacteria. As illustrated by the intracellular pathogens discussed above 
(most information on metabolic host responses comes from intracellular bacterial pathogens), some evidence exists that specific virulence factors and effector proteins may trigger responses that divert metabolic host reactions in support of the survival and growth of the individual pathogen. However, there is still little knowledge on the precise nature of these bacterial factors and even less on the interacting host targets causing the specific metabolic host changes.

The so far recognized specific host responses triggered by bacterial pathogens include: (a) induction of host cell enzymes which dampens the production or action of ROS and RNI, e.g., catalase and arginase, (b) further enhanced glucose uptake and GL which stimulate the host cell's anabolic activity (e.g., by increased production of nucleotides and amino acids), thus providing additional metabolites to the intracellular pathogens, (c) switch to enhanced glutaminolysis and citrate lyase reaction reinforcing fatty acid/lipid biosynthesis, (d) modulations in lipid metabolism, including changes in the biosynthesis of steroid and eicosanoid hormones that alter signaling pathways subsequently leading to metabolic shifts. An overview on these host cell responses is also given in Figure 5.

As we repeatedly mentioned, the majority of the specific host responses are, however, only observed in in vivo infection models, but not in the frequently used established cell lines which represent cancer cells or artificially transformed cells. Most of these host cells have already experienced massive metabolic changes which may be similar to those triggered by the bacterial pathogens and hence may mask pathogen-induced host responses.

\section{OUTLOOK}

This review illustrates that we are still far away from an in-depth understanding how the host (cell) metabolism is changed during infection by bacterial pathogens and how these metabolic changes affect the outcome of the infection. In the last decade especially cancer research has produced a wealth of new insights into the metabolism of mammalian cells and its complex regulation

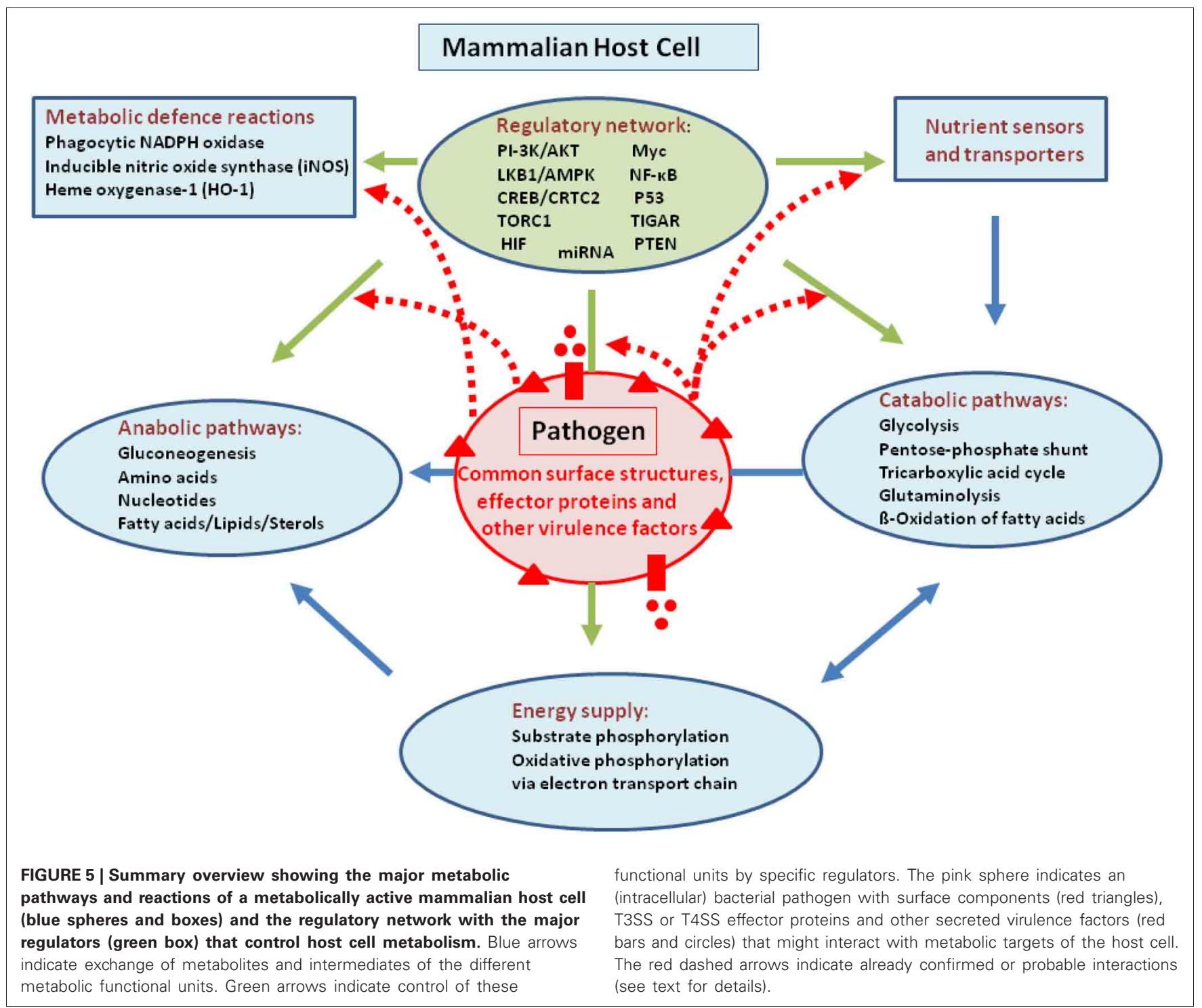


(for recent reviews, see Smolková et al., 2011; Chen and Russo, 2012): (a) The involvement of certain protooncogenes and tumor suppressors, e.g., c-Myc and p53, as important transcriptional regulators of the genes encoding key enzymes for metabolic pathways and of miRNAs controlling their synthesis is now wellestablished (Cheung and Vousden, 2010; Dang, 2010; Gaglio et al., 2011). (b) Multiple specific hormone and nutrient receptors ("transceptors") and signaling pathways have been shown to be involved in the regulation and modulation of cell metabolism and proliferation (Boulahbel et al., 2009; Dunlop and Tee, 2009; Hardie, 2011; Mosca et al., 2011).

Yet, not only these complex regulatory networks are of utmost importance for manipulating host cell metabolism, but also modulations in the activity of many enzymes involved in pathways of carbon-, nitrogen-, and energy metabolism. These modulations are often performed by phosphorylation, acetylation, or other post-translational reactions. In addition, many metabolic enzymes exist in different isoforms, and switches from one to another isoform may also alter metabolic fluxes.

It is likely, but not yet experimentally proven, that bacterial (especially intracellular) pathogens with their plethora of PAMPs and pathogenicity factors acting as effectors of host cell processes may influence the numerous regulatory host cell devices and/or the activity of metabolic enzymes by direct or indirect interaction. Indeed, some of the above described metabolic changes observed in host cells upon infection by the

\section{REFERENCES}

Adams, L. B., Dinauer, M. C., Morgenstern, D. E., and Krahenbuhl, J. L. (1997). Comparison of the roles of reactive oxygen and nitrogen intermediates in the host response to Mycobacterium tuberculosis using transgenic mice. Tuber. Lung Dis. 78, 237-246. doi: 10.1016/S0962-8479(97)90004-6

Aktories, K. (2011). Bacterial protein toxins that modify host regulatory GTPases. Nat. Rev. Microbiol. 9, 487-498. doi: 10.1038/nrmicro2592

Aktories, K., and Barbieri, J. T. (2005). Bacterial cytotoxins: targeting eukaryotic switches. Nat. Rev. Microbiol. 3, 397-410. doi: 10.1038/nrmicro1150

Alvesalo, J., Greco, D., Leinonen, M., Raitila, T., Vuorela, P., and Auvinen, P. (2008). Microarray analysis of a Chlamydia pneumoniae-infected human epithelial cell line by use of gene ontology hierarchy. J. Infect. Dis. 197, 156-162. doi: 10.1086/524142

Amer, A. O., Byrne, B. G., and Swanson, M. S. (2005). Macrophages rapidly transfer pathogens from lipid raft vacuoles to autophagosomes. Autophagy 1, 53-58. doi: 10.4161/auto.1.1.1589
Amirshahi, A., Wan, C., Beagley, K., Latter, J., Symonds, I., and Timms, P. (2011). Modulation of the Chlamydia trachomatis in vitro transcriptome response by the sex hormones estradiol and progesterone. BMC Microbiol. 11:150. doi: 10.1186/14712180-11-150

Andersen, J. L., and Kornbluth, S. (2013). The tangled circuitry of metabolism and apoptosis. Mol. Cell 49, 399-410. doi: 10.1016/j.molcel.2012.12.026

Antunes, L. C., Arena, E. T., Menendez, A., Han, J., Ferreira, R. B., Buckner, M. M., et al. (2011). Impact of salmonella infection on host hormone metabolism revealed by metabolomics. Infect. Immun. 79, 1759-1769. doi: 10.1128/IAI.01373-10

Appelberg, R. (2006). Macrophage nutriprive antimicrobial mechanisms. J. Leukoc. Biol. 79, 1117-1128. doi: 10.1189/jlb. 0206079

Baldwin, M. R., and Barbieri, J. T. (2005). The type III cytotoxins of Yersinia and Pseudomonas aeruginosa that modulate the actin cytoskeleton. Curr. Top. Microbiol. Immunol. 291, 147-166. doi: 10.1007/3-540-27511-8_8 different bacterial pathogens could be readily explained by such interactions.

In-depth investigations on the interactions of metabolic host targets with components of the bacterial pathogens and the impact of these interactions on host cell metabolism certainly represent an exciting research area which may significantly extend our understanding of bacterial pathogenesis. Classic high throughput ("omics") techniques will not suffice to solve these challenging problems. The adaptation and further development of new biochemical and physical techniques (in part described in this review) which allow the detection of cellular metabolic changes under in vivo conditions will be necessary for achieving this great task.

And last but not least—as repeatedly mentioned-it will be absolutely crucial to carry out these studies with appropriate in vivo models which make it possible to detect metabolic changes triggered by the bacterial pathogens during latent, acute, or chronic stages of infection.

\section{ACKNOWLEDGMENTS}

The authors wish to thank Hubert Hilbi and Rainer Haas for critical reading of the manuscript and for helpful discussions.

\section{SUPPLEMENTARY MATERIAL}

The Supplementary Material for this article can be found online at: http://www.frontiersin.org/Cellular_and_Infection_ Microbiology/10.3389/fcimb.2013.00024/abstract
Barel, M., Meibom, K., Dubail, I., Botella, J., and Charbit, A. (2012). Francisella tularensis regulates the expression of the amino acid transporter SLC1A5 in infected THP-1 human monocytes. Cell Microbiol. 14, 1769-1783. doi: 10.1111/j.14625822.2012.01837.x

Beisel, W. R. (1975). Metabolic response to infection. Annu. Rev. Med. 26, 9-20. doi: 10.1146/ annurev.me.26.020175.000301

Beisel, W. R. (1984). Metabolic effects of infection. Prog. Food Nutr. Sci. 8, 43-75.

Bensaad, K., Tsuruta, A., Selak, M. A., Vidal, M. N., Nakano, K., Bartrons, R., et al. (2006). TIGAR, a p53inducible regulator of glycolysis and apoptosis. Cell 126, 107-120. doi: 10.1016/j.cell.2006.05.036

Bertin, Y., Girardeau, J. P., Chaucheyras-Durand, F., Lyan, B., Pujos-Guillot, E., Harel, J., et al. (2011). Enterohaemorrhagic Escherichia coli gains a competitive advantage by using ethanolamine as a nitrogen source in the bovine intestinal content. Environ. Microbiol. 13, 365-377. doi: 10.1111/j.1462-2920.2010.02334.x

Birmingham, C. L., Canadien, V., Kaniuk, N. A., Steinberg, B. E., Higgins, D. E., and Brumell, J.
H. (2008). Listeriolysin O allows Listeria monocytogenes replication in macrophage vacuoles. Nature 451, 350-354. doi: 10.1038/ nature06479

Bogdan, C., Röllinghoff, M., and Diefenbach, A. (2000). Reactive oxygen and reactive nitrogen intermediates in innate and specific immunity. Curr. Opin. Immunol. 12, 64-76. doi: 10.1016/S0952-7915(99)00052-7

Boldrick, J. C., Alizadeh, A. A., Diehn, M., Dudoit, S., Liu, C. L., Belcher, C. E., et al. (2002). Stereotyped and specific gene expression programs in human innate immune responses to bacteria. Proc. Natl. Acad. Sci. U.S.A. 99, 972-977. doi: $10.1073 /$ pnas.231625398

Boulahbel, H., Durán, R. V., and Gottlieb, E. (2009). Prolyl hydroxylases as regulators of cell metabolism. Biochem. Soc. Trans. 37, 291-294. doi: 10.1042/BST0370291

Brennan, R. E., Russell, K., Zhang, G., and Samuel, J. E. (2004). Both inducible nitric oxide synthase and NADPH oxidase contribute to the control of virulent phase I Coxiella burnetii infections. Infect. Immun. 72, 6666-6675. doi: 10.1128/IAI.72.11.6666-6675.2004 
Brouard, S., Berberat, P. O., Tobiasch, E., Seldon, M. P., Bach, F. H., and Soares, M. P. (2002). Heme oxygenase-1-derived carbon monoxide requires the activation of transcription factor NF-kappa $\mathrm{B}$ to protect endothelial cells from tumor necrosis factoralpha-mediated apoptosis. J. Biol. Chem. 277, 17950-17961. doi: 10.1074/jbc.M108317200

Byrne, G. I. (2010). Chlamydia trachomatis strains and virulence: rethinking links to infection prevalence and disease severity. J. Infect. Dis. 201(Suppl. 2), S126-S133. doi: 10.1086/652398

Camejo, A., Carvalho, F., Reis, O., Leitão, E., Sousa, S., and Cabanes, D. (2011). The arsenal of virulence factors deployed by Listeria monocytogenes to promote its cell infection cycle. Virulence 2, 379-394. doi: 10.4161/viru.2.5.17703

Carey, K. L., Newton, H. J., Lührmann, A., and Roy, C. R. (2011). The Coxiella burnetii Dot/Icm system delivers a unique repertoire of type IV effectors into host cells and is required for intracellular replication. PLoS Pathog. 7:e1002056. doi: 10.1371/journal.ppat.1002056

Cawthraw, S., Pennings, J. L., Hodemaekers, H. M., de Jonge, R., Havelaar, A. H., Hoebee, B., et al. (2011). Gene expression profiles induced by Salmonella infection in resistant and susceptible mice. Microbes Infect. 13, 383-393. doi: 10.1016/j.micinf.2011.01.001

Cellier, M. F., Courville, P., and Campion, C. (2007). Nrampl phagocyte intracellular metal withdrawal defense. Microbes Infect. 9, 1662-1670. doi: 10.1016/j.micinf.2007.09.006

Chaston, J., and Goodrich-Blair, H. (2010). Common trends in mutualism revealed by model associations between invertebrates and bacteria. FEMS Microbiol. Rev. 34, 41-58. doi: 10.1111/j.1574-6976. 2009.00193.x

Chen, A. L., Johnson, K. A., Lee, J. K., Sütterlin, C., and Tan, M. (2012). CPAF: a Chlamydial protease in search of an authentic substrate. PLoS Pathog. 8:e1002842. doi: 10.1371/journal.ppat.1002842

Chen, B., Li, H., Zeng, X., Yang, P., Liu, X., Zhao, X., et al. (2012). Roles of microRNA on cancer cell metabolism. J. Transl. Med. 10:228. doi: 10.1186/1479-5876-10-228

Chen, J. Q., and Russo, J. (2012). Dysregulation of glucose transport, glycolysis, TCA cycle and glutaminolysis by oncogenes and tumor suppressors in cancer cells.
Biochim. Biophys. Acta 1826, 370-384.

Cheng, T., Sudderth, J., Yang, C., Mullen, A. R., Jin, E. S., Matés, J. M., et al. (2011). Pyruvate carboxylase is required for glutamine-independent growth of tumor cells. Proc. Natl. Acad. Sci. U.S.A.108, 8674-8679. doi: 10.1073/pnas.1016627108

Cheung, E. C., and Vousden, K. H. (2010). The role of $\mathrm{p} 53$ in glucose metabolism. Curr. Opin. Cell Biol. 22, 186-191. doi: 10.1016/j.ceb.2009.12.006

Chico-Calero, I., Suárez, M., GonzálezZorn, B., Scortti, M., Slaghuis, J., Goebel, W., et al. (2002). Hpt, a bacterial homolog of the microsomal glucose- 6-phosphate translocase, mediates rapid intracellular proliferation in Listeria. Proc. Natl. Acad. Sci. U.S.A. 99, 431-436. doi: 10.1073/pnas.012363899

Chien, M., Morozova, I., Shi, S., Sheng, H., Chen, J., Gomez, S. M., et al. (2004). The genomic sequence of the accidental pathogen Legionella pneumophila. Science 305, 1966-1968. doi: 10.1126/science.1099776

Cohen, P., Bouaboula, M., Bellis, M., Baron, V., Jbilo, O., Poinot-Chazel, C., et al. (2000). Monitoring cellular responses to Listeria monocytogenes with oligonucleotide arrays. J. Biol. Chem. 275, 11181-11190. doi: 10.1074/jbc.275.15.11181

Dang, C. V. (2010). Enigmatic MYC conducts an unfolding systems biology symphony. Genes Cancer 1, 526-531. doi: $10.1177 / 1947601910378742$

Das, P., Lahiri, A., Lahiri, A., and Chakravortty, D. (2010). Modulation of the arginase pathway in the context of microbial pathogenesis: a metabolic enzyme moonlighting as an immune modulator. PLoS Pathog. 6:e1000899. doi: 10.1371/journal.ppat.1000899

de Carvalho, L. P., Fischer, S. M., Marrero, J., Nathan, C., Ehrt, S., and Rhee, K. Y. (2010). Metabolomics of Mycobacterium tuberculosis reveals compartmentalized co-catabolism of carbon substrates. Chem. Biol. $17,1122-1131$.

de las Heras, A., Cain, R. J., Bielecka, M. K., and Vázquez-Boland, J. A. (2011). Regulation of Listeria virulence: PrfA master and commander. Curr. Opin. Microbiol. 14, 118-127. doi: 10.1016/j.mib. 2011.01.005

Dean, P. (2011). Functional domains and motifs of bacterial type III effector proteins and their roles in infection. FEMS Microbiol. Rev.
35, 1100-1125. doi: 10.1111/j.15746976.2011.00271.x

Detweiler, C. S., Cunanan, D. B., and Falkow, S. (2001). Host microarray analysis reveals a role for the Salmonella response regulator phoP in human macrophage cell death. Proc. Natl. Acad. Sci. U.S.A. 98, 5850-5855. doi: 10.1073/pnas.091110098

Dunlop, E. A., and Tee, A. R. (2009). Mammalian target of rapamycin complex 1: signalling inputs, substrates and feedback mechanisms. Cell. Signal. 21, 827-835. doi: 10.1016/j.cellsig.2009.01.012

Ehrt, S., Schnappinger, D., Bekiranov, S., Drenkow, J., Shi, S., Gingeras, T. R., et al. (2001). Reprogramming of the macrophage transcriptome in response to interferon-gamma and Mycobacterium tuberculosis: signaling roles of nitric oxide synthase- 2 and phagocyte oxidase. J. Exp. Med. 194, 1123-1140. doi: 10.1084/jem.194.8.1123

Eickhoff, M., Thalmann, J., Hess, S., Martin, M., Laue, T., Kruppa, J., et al. (2007). Host cell responses to Chlamydia pneumoniae in gamma interferon-induced persistence overlap those of productive infection and are linked to genes involved in apoptosis, cell cycle, and metabolism. Infect. Immun. 75, 2853-2863. doi: 10.1128/IAI.01045-06

Eisenreich, W., Dandekar, T., Heesemann, J., and Goebel, W. (2010). Carbon metabolism of intracellular bacterial pathogens and possible links to virulence. Nat. Rev. Microbiol. 8, 401-412. doi 10.1038/nrmicro2351

Erickson, J. W., and Cerione, R. A. (2010). Glutaminase: a hot spot for regulation of cancer cell metabolism. Oncotarget 1, 734-740.

Eylert, E., Schär, J., Mertins, S., Stoll, R., Bacher, A., Goebel, W., et al. (2008). Carbon metabolism of Listeria monocytogenes growing inside macrophages. Mol Microbiol. 69, 1008-1017. doi: 10.1111/j.1365-2958.2008.06337.x

Fang, F. C. (2011). Antimicrobial actions of reactive oxygen species. MBio 2:e00141-11. doi 10.1128/mBio.00141-11

Farbrother, P., Wagner, C., Na, J., Tunggal, B., Morio, T., Urushihara, H., et al. (2006). Dictyostelium transcriptional host cell response upon infection with Legionella. Cell. Microbiol. 8, 438-456. doi: 10.1111/j.1462-5822.2005.00633.x

Fedotcheva, N. I., Sokolov, A. P., and Kondrashova, M. N. (2006).
Nonenzymatic formation of succinate in mitochondria under oxidative stress. Free Radic. Biol. Med. 41, 56-64. doi: 10.1016/j. freeradbiomed.2006.02.012

Fuchs, T. M., Eisenreich, W., Heesemann, J., and Goebel, W. (2012). Metabolic adaptation of human pathogenic and related nonpathogenic bacteria to extraand intracellular habitats. FEMS Microbiol. Rev. 36, 435-462. doi: 10.1111/j.1574-6976.2011.00301.x

Fukuda, E. Y., Lad, S. P., Mikolon, D. P., Iacobelli-Martinez, M., and $\mathrm{Li}, \mathrm{E}$. (2005). Activation of lipid metabolism contributes to interleukin-8 production during Chlamydia trachomatis infection of cervical epithelial cells. Infect. Immun. 73, 4017-4024. doi: 10.1128/IAI.73.7.4017-4024.2005

Gaglio, D., Metallo, C. M., Gameiro, P. A., Hiller, K., Danna, L. S., Balestrieri, C., et al. (2011). Oncogenic K-Ras decouples glucose and glutamine metabolism to support cancer cell growth. Mol. Syst. Biol. 7, 523. doi: 10.1038/msb.2011.56

Gao, P., Tchernyshyov, I., Chang, T. C. Lee, Y. S., Kita, K., Ochi, T., et al. (2009). c-Myc suppression of miR$23 \mathrm{a} / \mathrm{b}$ enhances mitochondrial glutaminase expression and glutamine metabolism. Nature 458, 762-765. doi: 10.1038/nature07823

Garner, B., Mellor, H. R., Butters, T. D., Dwek, R. A., and Platt, F. M. (2002). Modulation of THP-1 macrophage and cholesterol-loaded foam cell apolipoprotein E levels by glycosphingolipids. Biochem. Biophys. Res. Commun. 290, 1361-1367. doi 10.1006/bbrc. 2002.6356

Gekara, N. O., Groebe, L., Viegas, N., and Weiss, S. (2008). Listeria monocytogenes desensitizes immune cells to subsequent $\mathrm{Ca}^{2+}$ signaling via listeriolysin O-induced depletion of intracellular $\mathrm{Ca}^{2+}$ stores. Infect. Immun. 76, 857-862. doi: 10.1128/IAI.00622-07

Gillmaier, N., Götz, A., Schulz, A., Eisenreich, W., and Goebel, W. (2012). Metabolic responses of primary and transformed cells to intracellular Listeria monocytogenes. PLoS ONE 7:e52378. doi 10.1371/journal.pone.0052378

Glatz, J. F., Luiken, J. J., and Bonen, A. (2010). Membrane fatty acid transporters as regulators of lipid metabolism: implications for metabolic disease. Physiol. Rev. 90, 367-417. doi: 10.1152/physrev.00003.2009 Goldfine, H., and Wadsworth, S. J. (2002). Macrophage 
intracellular signaling induced by Listeria monocytogenes. Microbes Infect. 4, 1335-1343. doi: 10.1016/S1286-4579(02)00011-4

Gordan, J. D., Thompson, C. B., and Simon, M. C. (2007). HIF and cMyc: sibling rivals for control of cancer cell metabolism and proliferation. Cancer Cell 12, 108-113. doi: 10.1016/j.ccr.2007.07.006

Haenssler, E., and Isberg, R. R. (2011). Control of host cell phosphorylation by Legionella pneumophila. Front. Microbiol. 2:64. doi: 10.3389/fmicb.2011.00064

Hagedorn, M., Rohde, K. H., Russell, D. G., and Soldati, T. (2009). Infection by tubercular mycobacteria is spread by nonlytic ejection from their amoeba hosts. Science 323, 1729-1733. doi: $10.1126 /$ science.1169381

Han, J., Danell, R. M., Patel, J. R., Gumerov, D. R., Scarlett, C. O., Speir, J. P., et al. (2008). Towards high-throughput metabolomics using ultrahigh-field Fourier transform ion cyclotron resonance mass spectrometry. Metabolomics 4, 128-140. doi: 10.1007/s11306-008-0104-8

Handley, S. A., and Miller, V. L. (2007). General and specific host responses to bacterial infection in Peyer's patches: a role for stromelysin-1 (matrix metalloproteinase-3) during Salmonella enterica infection. Mol. Microbiol. 64, 94-110. doi: 10.1111/j.1365-2958.2007.05635.x

Hardie, D. G. (2011). Sensing of energy and nutrients by AMPactivated protein kinase. Am. J. Clin. Nutr. 93, 891S-896S. doi: 10.3945/ajcn.110.001925

Hardt, W. D., and Galán, J. E. (1997). A secreted Salmonella protein with homology to an avirulence determinant of plant pathogenic bacteria. Proc. Natl. Acad. Sci. U.S.A. 94, 9887-9892. doi: 10.1073/pnas.94.18.9887

Hartmann, H., Eltzschig, H. K., Wurz, H., Hantke, K., Rakin, A., Yazdi, A. S., et al. (2008). Hypoxia-independent activation of HIF-1 by enterobacteriaceae and their siderophores. Gastroenterology 134, 756-767. doi: 10.1053/j.gastro.2007.12.008

Hellwig-Bürgel, T., Stiehl, D. P., Wagner, A. E., Metzen, E., and Jelkmann, W. (2005). Review: hypoxia-inducible factor-1 (HIF-1): a novel transcription factor in immune reactions. J. Interferon Cytokine Res. 25, 297-310. doi: 10.1089/jir.2005.25.297

Herikstad, H., Motarjemi, Y., and Tauxe, R. V. (2002). Salmonella surveillance: a global survey of public health serotyping. Epidemiol. Infect. 129, 1-8. doi: 10.1017/S0950268802006842

Hervet, E., Charpentier, X., Vianney, A., Lazzaroni, J. C., Gilbert, C., Atlan, D., and Doublet, P. (2011). Protein kinase LegK2 is a type IV secretion system effector involved in endoplasmic reticulum recruitment and intracellular replication of Legionella pneumophila. Infect. Immun. 79, 1936-1950. doi: 10.1128/IAI.00805-10

Heym, C., Liu, N., Gleich, A., Oberst, P., and Kummer, W. (1993). Immunohistochemical evidence for different pathways immunoreactive to substance $\mathrm{P}$ and calcitonin gene-related peptide (CGRP) in the guinea-pig stellate ganglion. Cell Tissue Res. 272, 563-574. doi: 10.1007/BF00318563

Hilbi, H. (2006). Modulation of phosphoinositide metabolism by pathogenic bacteria. Cell. Microbiol. 8, 1697-1706. doi: 10.1111/j.1462-5822.2006.00793.x

Hill, J., and Samuel, J. E. (2011). Coxiella burnetii acid phosphatase inhibits the release of reactive oxygen intermediates in polymorphonuclear leukocytes. Infect. Immun. 79, 414-420. doi: 10.1128/IAI.01011-10

Holsbeeks, I., Lagatie, O., Van Nuland, A., Van de Velde, S., and Thevelein, J. M. (2004). The eukaryotic plasma membrane as a nutrient-sensing device. Trends Biochem. Sci. 29, 556-564. doi: 10.1016/j.tibs.2004.08.010

Howe, D., and Heinzen, R. A. (2006). Coxiella burnetii inhabits a cholesterol-rich vacuole and influences cellular cholesterol metabolism. Cell. Microbiol. 8, 496-507. doi: 10.1111/j.1462-5822.2005.00641.x

Howe, D., and Mallavia, L. P. (1999). Coxiella burnetii infection increases transferrin receptors on J774A.1 cells. Infect. Immun. 67, 3236-3241.

Hsu, P. P., and Sabatini, D. M. (2008). Cancer cell metabolism: Warburg and beyond. Cell 134, 703-707. doi: 10.1016/j.cell.2008.08.021

Hunter, R. L., Jagannath, C., and Actor, J. K. (2007). Pathology of postprimary tuberculosis in humans and mice: contradiction of long-held beliefs. Tuberculosis (Edinb.) 87, 267-278. doi: 10.1016/j.tube.2006.11.003

Hyde, R., Taylor, P. M., and Hundal, H. S. (2003). Amino acid transporters: roles in amino acid sensing and signaling in animal cells. Biochem. J. 373, 1-18. doi: 10.1042/BJ20030405
Isberg, R. R., O'Connor, T. J., and Heidtman, M. (2009). The Legionella pneumophila replication vacuole: making a cosy niche inside host cells. Nat. Rev. Microbiol. 7, 13-24. doi: 10.1038/nrmicro1967 Jantsch, J., Cheminay, C., Chakravortty, D., Lindig, T., Hein, J., and Hensel, M. (2003). Intracellular activities of Salmonella enterica in murine dendritic cells. Cell Microbiol. 5, 933-945. doi: 10.1046/j.1462-5822.2003.00334.x

Jenner, R. G., and Young, R. A. (2005). Insights into host responses against pathogens from transcriptional profiling. Nat. Rev. Microbiol. 3, 281-294. doi: 10.1038/nrmicro1126

Jouaville, L. S., Pinton, P., Bastianutto, C., Rutter, G. A., and Rizzuto, R. (1999). Regulation of mitochondrial ATP synthesis by calcium: evidence for a long-term metabolic priming. Proc. Natl. Acad. Sci. U.S.A. 96, 13807-13812. doi: 10.1073/pnas.96.24.13807

Karavolos, M. H., Spencer, H., Bulmer, D. M., Thompson, A., Winzer, K., Williams, P., et al. (2008). Adrenaline modulates the global transcriptional profile of Salmonella revealing a role in the antimicrobial peptide and oxidative stress resistance responses. BMC Genomics 9:458. doi: 10.1186/1471-2164-9458

Kastner, R., Dussurget, O., Archambaud, C., Kernbauer, E., Soulat, D., Cossart, P., et al. (2011). LipA, a tyrosine and lipid phosphatase involved in the virulence of Listeria monocytogenes. Infect. Immun. 79, 2489-2498. doi: 10.1128/IAI.05073-11

Kawai, T., and Akira, S. (2011) Toll-like receptors and their crosstalk with other innate receptors in infection and immunity. Immunity 34, 637-650. doi: 10.1016/j.immuni.2011.05.006

Kayal, S., and Charbit, A. (2006). Listeriolysin O: a key protein of Listeria monocytogenes with multiple functions. FEMS Microbiol. Rev. 30, 514-529. doi: 10.1111/j.15746976.2006.00021.x

Kendall, S. L., Rison, S. C., Movahedzadeh, F., Frita, R., and Stoker, N. G. (2004). What do microarrays really tell us about M. tuberculosis? Trends Microbiol. 12, 537-544. doi: 10.1016/j.tim.2004.10.005

Kim, M. J., Wainwright, H. C., Locketz, M., Bekker, L. G., Walther, G. B., Dittrich, C., et al. (2010). Caseation of human tuberculosis granulomas correlates with elevated host lipid metabolism.
EMBO Mol. Med. 2, 258-274. doi: 10.1002/emmm.201000079

Klionsky, D. J. (2007). Autophagy: from phenomenology to molecular understanding in less than a decade. Nat. Rev. Mol. Cell Biol. 8, 931-937. doi: $10.1038 / \mathrm{nrm} 2245$

Klip, A. (2009). The many ways to regulate glucose transporter 4. Appl. Physiol. Nutr. Metab. 34, 481-487. doi: 10.1139/H09-047

Knodler, L. A., Finlay, B. B., and Steele-Mortimer, O. (2005). The Salmonella effector protein SopB protects epithelial cells from apoptosis by sustained activation of Akt. J. Biol. Chem. 280, 9058-9064. doi: 10.1074/jbc.M412588200

Korf, J., Stoltz, A., Verschoor, J., De Baetselier, P., and Grooten, J. (2005). The Mycobacterium tuberculosis cell wall component mycolic acid elicits pathogen-associated host innate immune responses. Eur. J. Immunol. 35, 890-900. doi: 10.1002/eji.200425332

Kuijl, C., Savage, N. D., Marsman, M., Tuin, A. W., Janssen, L., Egan, D. A., et al. (2007). Intracellular bacterial growth is controlled by a kinase network around PKB/AKT1. Nature 450, 725-730. doi: 10.1038 /nature 06345

Lahiri, A., Das, P., and Chakravortty, D. (2008). Arginase modulates Salmonella induced nitric oxide production in RAW264.7 macrophages and is required for Salmonella pathogenesis in mice model of infection. Microbes Infect. 10, 1166-1174. doi: 10.1016/j.micinf.2008.06.008

Lecuit, M., Sonnenburg, J. L., Cossart, P., and Gordon, J. I. (2007). Functional genomic studies of the intestinal response to a foodborne enteropathogen in a humanized gnotobiotic mouse model. J. Biol. Chem. 282, 15065-15072. doi: 10.1074/jbc.M610926200

Lee, S. H., Oh, T., Jeon, B. Y., Kwak, E. Y., Shim, W. S., Cho, S. N., et al. (2009). Tissue-specific changes in mRNA expression of $\mathrm{Abc}$ and Slc transporters in murine pulmonary tuberculosis. Xenobiotica 39, 738-748. doi: 10.1080/00498250903089829

Levine, A. J., and Puzio-Kuter, A. M. (2010). The control of the metabolic switch in cancers by oncogenes and tumor suppressor genes. Science 330, 1340-1344. doi: 10.1126/science.1193494

Li, Z., Dugan, A. S., Bloomfield, G., Skelton, J., Ivens, A., Losick, V., et al. (2009). The amoebal MAP kinase response to Legionella pneumophila is regulated by DupA. 
Cell Host Microbe 6, 253-267. doi: 10.1016/j.chom.2009.08.005

Liu, J., and Feng, Z. (2012). PTEN, energy metabolism and tumor suppression. Acta Biochim. Biophys. Sin. 44, 629-631. doi: 10.1093/abbs/gms048

Liu, W., Le, A., Hancock, C., Lane, A. N., Dang, C. V., Fan, T. W., et al. (2012). Reprogramming of proline and glutamine metabolism contributes to the proliferative and metabolic responses regulated by oncogenic transcription factor c-MYC. Proc. Natl. Acad. Sci. U.S.A. 109, 8983-8988. doi: 10.1073/pnas.1203244109

Liu, X., Lu, R., Xia, Y., and Sun, J. (2010a). Global analysis of the eukaryotic pathways and networks regulated by Salmonella typhimurium in mouse intestinal infection in vivo. BMC Genomics 11:722. doi: 10.1186/1471-2164-11-722

Liu, X., Lu, R., Xia, Y., Wu, S., and Sun, J. (2010b). Eukaryotic signaling pathways targeted by Salmonella effector protein AvrA in intestinal infection in vivo. BMC Microbiol. 10:326. doi: 10.1186/1471-2180-10326

Lopez, C. A., Winter, S. E., RiveraChávez, F., Xavier, M. N., Poon, V., Nuccio, S. P., et al. (2012). Phage-mediated acquisition of a type III secreted effector protein boosts growth of salmonella by nitrate respiration. MBio 3:e014312. doi: $10.1128 / \mathrm{mBio} .00143-12$

Losick, V. P., Haenssler, E., Moy, M. Y., and Isberg, R. R. (2010). LnaB: a Legionella pneumophila activator of NF-kappaB. Cell. Microbiol. 12, 1083-1097. doi: 10.1111/j.14625822.2010.01452.x

Losick, V. P., and Isberg, R. R. (2006). NF- $\kappa$ B translocation prevents host cell death after low-dose challenge by Legionella pneumophila. J. Exp. Med. 203, 2177-2189. doi: 10.1084/jem.20060766

Lowenstein, C. J., and Padalko, E. (2004). iNOS (NOS2) at a glance. J. Cell Sci. 117, 2865-2867. doi: $10.1242 /$ jcs. 01166

Lupp, C., Robertson, M. L., Wickham, M. E., Sekirov, I., Champion, O. L., Gaynor, E. C., et al. (2007). Host-mediated inflammation disrupts the intestinal microbiota and promotes the overgrowth of Enterobacteriaceae. Cell Host Microbe 2, 119-129. doi: 10.1016/j.chom.2007.06.010

Macallan, D. C., McNurlan, M. A., Kurpad, A. V., de Souza, G., Shetty, P. S., Calder, A. G., et al. (1998). Whole body protein metabolism in human pulmonary tuberculosis and under nutrition: evidence for anabolic block in tuberculosis. Clin. Sci. (Lond.) 94, 321-331.

MacFarlane, A. S., Schwacha, M. G., and Eisenstein, T. K. (1999). In vivo blockage of nitric oxide with aminoguanidine inhibits immunosuppression induced by an attenuated strain of Salmonella typhimurium, potentiates Salmonella infection, and inhibits macrophage and polymorphonuclear leukocyte influx into the spleen. Infect. Immun. 67, 891-898.

Mahapatra, S., Ayoubi, P., and Shaw, E. I. (2010). Coxiella burnetii Nine Mile II proteins modulate gene expression of monocytic host cells during infection. BMC Microbiol. 10:244. doi: 10.1186/1471-2180-10244

Manger, I. D., and Relman, D. A. (2000). How the host 'sees' pathogens: global gene expression responses to infection. Curr. Opin. Immunol. 12, 215-218. doi: 10.1016/S0952-7915(99)00077-1

Marohnic, C. C., Panda, S. P., Martásek, P., and Masters, B. S. (2006). Diminished FAD binding in the $\mathrm{Y} 459 \mathrm{H}$ and V492E Antley-Bixler syndrome mutants of human cytochrome P450 reductase. J. Biol. Chem. 281, 35975-35982. doi: 10.1074/jbc.M607095200

Mastroeni, P., Vazquez-Torres, A., Fang, F. C., Xu, Y., Khan, S., Hormaeche, C. E., et al. (2000). Antimicrobial actions of the NADPH phagocyte oxidase and inducible nitric oxide synthase in experimental salmonellosis. II. Effects on microbial proliferation and host survival in vivo. J. Exp. Med. 192, 237-248. doi: 10.1084/jem.192.2.237

Mathis, D., and Shoelson, S. E. (2011) Immunometabolism: an emerging frontier. Nat. Rev. Immunol. 11, 81. doi: $10.1038 /$ nri2922

Mauro, C., Leow, S. C., Anso, E., Rocha, S., Thotakura, A. K., Tornatore, L., et al. (2011). NF- $\kappa B$ controls energy homeostasis and metabolic adaptation by upregulating mitochondrial respiration. Nat. Cell Biol. 13, 1272-1279. doi: 10.1038/ncb2324

McClarty, G. (1994). Chlamydiae and the biochemistry of intracellular parasitism. Trends Microbiol. 2, 157-164. doi: 10.1016/0966-842X(94)90665-3

Mead, P. S., Slutsker, L., Dietz, V., McCaig, L. F., Bresee, J. S., Shapiro, C., et al. (1999). Food-related illness and death in the United States. Emerg. Infect. Dis. 5, 607-625. doi: 10.3201/eid0505.990502
Moest, T. P., and Méresse, S. (2013) Salmonella T3SSs: successful mission of the secret(ion) agents. Curr. Opin. Microbiol. 16, 38-44. doi: 10.1016/j.mib.2012.11.006

Mosca, E., Barcella, M., Alfieri, R., Bevilacqua, A., Canti, G., and Milanesi, L. (2011). Systems biology of the metabolic network regulated by the Akt pathway. Biotechnol. Adv. 30, 131-141. doi: 10.1016/j.biotechadv.2011.08.004

Muñoz-Elías, E. J., and McKinney, J. D. (2005). Mycobacterium tuberculosis isocitrate lyases 1 and 2 are jointly required for in vivo growth and virulence. Nat. Med. 11, 638-644. doi: 10.1038/nm1252

Musat, N., Foster, R., Vagner, T., Adam, B., and Kuypers, M. M. (2012). Detecting metabolic activities in single cells, with emphasis on nanoSIMS. FEMS Microbiol. Rev. 36, 486-511. doi: 10.1111/j.15746976.2011.00303.x

Nairz, M., Fritsche, G., Crouch, M. L., Barton, H. C., Fang, F. C., and Weiss, G. (2009). Slc1lal limits intracellular growth of Salmonella enterica sv. Typhimurium by promoting macrophage immune effector functions and impairing bacterial iron acquisition. Cell. Microbiol. 11, 1365-1381. doi: 10.1111/j.14625822.2009.01337.x

Nathan, C., and Shiloh, M. U. (2000). Reactive oxygen and nitrogen intermediates in the relationship between mammalian hosts and microbial pathogens. Proc. Natl. Acad. Sci. U.S.A. 97, 8841-8848. doi: $10.1073 /$ pnas.97.16.8841

Natividad, A., Freeman, T. C., Jeffries, D., Burton, M. J., Mabey, D. C. Bailey, R. L., et al. (2010). Human conjunctival transcriptome analysis reveals the prominence of innate defense in Chlamydia trachomatis infection. Infect. Immun. 78, 4895-4911. doi: 10.1128/IAI. 00844-10

Nau, G. J., Richmond, J. F., Schlesinger, A., Jennings, E. G., Lander, E. S., and Young, R. A. (2002) Human macrophage activation programs induced by bacterial pathogens. Proc. Natl. Acad. Sci. U.S.A. 99, 1503-1508. doi: 10.1073/pnas.022649799

Neyrolles, O., Hernández-Pando, R., Pietri-Rouxel, F., Fornès, P. Tailleux, L., Barrios Payán, J. A., et al. (2006). Is adipose tissue a place for Mycobacterium tuberculosis persistence? PLoS ONE 1:e43. doi: 10.1371/journal. pone. 0000043

Ng, V. H., Cox, J. S., Sousa, A. O., MacMicking, J. D., and McKinney,
J. D. (2004). Role of KatG catalaseperoxidase in mycobacterial pathogenesis: countering the phagocyte oxidative burst. Mol. Microbiol. 52, 1291-1302. doi: 10.1111/j.1365-2958.2004.04078.x

Niedergang, F., Sirard, J. C., Blanc, C. T., and Kraehenbuhl, J. P. (2000). Entry and survival of Salmonella typhimurium in dendritic cells and presentation of recombinant antigens do not require macrophagespecific virulence factors. Proc. Natl. Acad. Sci. U.S.A. 97, 14650-14655. doi: 10.1073/pnas.97.26.14650

O'Neill, L. A., and Hardie, D. G. (2013). Metabolism of inflammation limited by AMPK and pseudostarvation. Nature 493, 346-355. doi: $10.1038 /$ nature 11862

Otto, G. P., Wu, M. Y., Clarke, M., Lu, H., Anderson, O. R., Hilbi, H., et al. (2004). Macroautophagy is dispensable for intracellular replication of Legionella pneumophila in Dictyostelium discoideum. Mol. Microbiol. 51, 63-72. doi: 10.1046/j.1365-2958.2003.03826.x

Ouellette, S. P., Dorsey, F. C., Moshiach, S., Cleveland, J. L., and Carabeo, R. A. (2011). Chlamydia speciesdependent differences in the growth requirement for lysosomes. PLoS ONE 6:e16783. doi: 10.1371/journal.pone.0016783

Paulin, S. M., Watson, P. R., Benmore, A. R., Stevens, M. P., Jones, P. W., Villarreal-Ramos, B., et al. (2002). Analysis of Salmonella enterica serotype-host specificity in calves: avirulence of $S$. enterica serotype gallinarum correlates with bacterial dissemination from mesenteric lymph nodes and persistence in vivo. Infect. Immun. 70, 6788-6797. doi: 10.1128/IAI.70.12.6788-6797.2002

Pikuleva, I. A. (2006). Cholesterolmetabolizing cytochromes P450. Drug Metab. Dispos. 34, 513-520. doi: $10.1124 / \mathrm{dmd} .105 .008789$

Pizarro-Cerdá, J., and Cossart, P. (2004). Subversion of phosphoinositide metabolism by intracellular bacterial pathogens. Nat. Cell Biol. 6, 1026-1033. doi: 10.1038/ncb1104-1026

Price, C. T., Al-Quadan, T., Santic, M., Rosenshine, I., and Abu Kwaik, Y. (2011). Host proteasomal degradation generates amino acids essential for intracellular bacterial growth. Science 334, 1553-1557. doi: 10.1126/science.1212868

Pullinger, G. D., Paulin, S. M. Charleston, B., Watson, P. R., Bowen, A. J., Dziva, F., et al. (2007). Systemic translocation of Salmonella enterica serovar Dublin 
in cattle occurs predominantly via efferent lymphatics in a cell-free niche and requires type III secretion system 1 (T3SS-1) but not T3SS-2. Infect. Immun. 75, 5191-5199. doi: 10.1128/IAI.00784-07

Rabinowitz, J. D., and White, E. (2010). Autophagy and metabolism. Science 330, 1344-1348. doi: 10.1126/science.1193497

Rathore, M. G., Saumet, A., Rossi, J. F., de Bettignies, C., Tempé, D., Lecellier, C. H., et al. (2012). The NF-кB member p65 controls glutamine metabolism through miR-23a. Int. J. Biochem. Cell Biol. 44, 1448-1456. doi: 10.1016/j.biocel.2012.05.011

Ren, Q., Robertson, S. J., Howe, D., Barrows, L. F., and Heinzen, R. A. (2003). Comparative DNA microarray analysis of host cell transcriptional responses to infection by Coxiella burnetii or Chlamydia trachomatis. Ann. N.Y. Acad. Sci. 990, 701-713. doi: 10.1111/j.17496632.2003.tb07447.x

Rhee, K. Y., de Carvalho, L. P., Bryk, R., Ehrt, S., Marrero, J., Park, S. W., et al. (2011). Central carbon metabolism in Mycobacterium tuberculosis: an unexpected frontier. Trends Microbiol. 19, 307-314. doi: 10.1016/j.tim.2011.03.008

Richards, J. R. (1980). Current concepts in the metabolic responses to injury, infection and starvation. Proc. Nutr. Soc. 39, 113-123. doi: 10.1079/PNS19800019

Robertson, D. K., Gu, L., Rowe, R. K., and Beatty, W. L. (2009). Inclusion biogenesis and reactivation of persistent Chlamydia trachomatis requires host cell sphingolipid biosynthesis. PLoS Pathog. 5:e1000664. doi: 10.1371/journal.ppat.1000664

Rosenberger, C. M., Scott, M. G., Gold, M. R., Hancock, R. E., and Finlay, B. B. (2000). Salmonella typhimurium infection and lipopolysaccharide stimulation induce similar changes in macrophage gene expression. J. Immunol. 164, 5894-5904.

Rupp, J., Gieffers, J., Klinger, M., van Zandbergen, G., Wrase, R., Maass, M., et al. (2007). Chlamydia pneumoniae directly interferes with HIF-1alpha stabilization in human host cells. Cell. Microbiol. 9, 2181-2191. doi: 10.1111/j.1462-5822.2007.00948.x

Russell, D. G. (2007). Who puts the tubercle in tuberculosis. Nat. Rev. Microbiol. 5, 39-47. doi: 10.1038/nrmicro1538

Russell, D. G., Mwandumba, H. C., and Rhoades, E. E. (2002). Mycobacterium and the coat of many lipids. J. Cell Biol. 158, 421-426. doi: 10.1083/jcb.200205034

Santos, R. L., Raffatellu, M., Bevins, C. L., Adams, L. G., Tükel, C., Tsolis, R. M., et al. (2009). Life in the inflamed intestine, Salmonella style. Trends Microbiol. 17, 498-506. doi: 10.1016/j.tim. 2009.08.008

Santos, R. L., Schoffelmeer, J. A., Tsolis, R. M., Gutiérrez-Pabello, J. A., Bäumler, A. J., and Adams, L. G. (2002). Salmonella serotype Typhimurium infection of bovine Peyer's patches down-regulates plasma membrane calciumtransporting ATPase expression. J. Infect. Dis. 186, 372-378. doi: 10.1086/341509

Savijoki, K., Alvesalo, J., Vuorela, P., Leinonen, M., and Kalkkinen, N. (2008). Proteomic analysis of Chlamydia pneumoniaeinfected HL cells reveals extensive degradation of cytoskeletal proteins. FEMS Immunol. Med. Microbiol. 54, 375-384. doi: 10.1111/j.1574-695X.2008.00488.x

Shackelford, D. B., and Shaw, R. J. (2009). The LKB1-AMPK pathway: metabolism and growth control in tumour suppression. Nat. Rev. Cancer 9, 563-575. doi: 10.1038/nrc2676

Shaw, M. H., Reimer, T., Kim, Y. G., and Nuñez, G. (2008). NOD-like receptors (NLRs): bona fide intracellular microbial sensors. Curr. Opin. Immunol. 20, 377-382. doi: 10.1016/j.coi.2008.06.001

Shi, L., Chowdhury, S. M., Smallwood, H. S., Yoon, H., Mottaz-Brewer, H. M., Norbeck, A. D., et al. (2009). Proteomic investigation of the time course responses of RAW 264.7 macrophages to infection with Salmonella enterica. Infect. Immun. 77, 3227-3233. doi: 10.1128/IAI.00063-09

Shiloh, M. U., MacMicking, J. D., Nicholson, S., Brause, J. E., Potter, S., Marino, M., et al. (1999). Phenotype of mice and macrophages deficient in both phagocyte oxidase and inducible nitric oxide synthase. Immunity 10, 29-38. doi: 10.1016/S1074-7613(00)80004-7

Shiloh, M. U., Manzanillo, P., and Cox, J. S. (2008). Mycobacterium tuberculosis senses host-derived carbon monoxide during macrophage infection. Cell Host Microbe 3, 323-330. doi: 10.1016/j.chom.2008.03.007

Shin, J. H., Yang, J. Y., Jeon, B. Y., Yoon, Y. J., Cho, S. N., Kang, Y. H., et al. (2011). ${ }^{1} \mathrm{H}$
NMR-based metabolomic profiling in mice infected with Mycobacterium tuberculosis. J. Proteome Res. 10, 2238-2247. doi: $10.1021 / \mathrm{pr} 101054 \mathrm{~m}$

Shin, S., and Roy, C. R. (2008). Host cell processes that influence the intracellular survival of Legionella pneumophila. Cell. Microbiol. 10, 1209-1220. doi 10.1111/j.1462-5822.2008.01145.x

Shui, W., Gilmore, S. A., Sheu, L., Liu, J., Keasling, J. D., and Bertozzi, C. R. (2009). Quantitative proteomic profiling of host-pathogen interactions: the macrophage response to Mycobacterium tuberculosis lipids. J. Proteome Res. 8, 282-289. doi: 10.1021/pr800422e

Siemsen, D. W., Kirpotina, L. N., Jutila, M. A., and Quinn, M. T. (2009). Inhibition of the human neutrophi NADPH oxidase by Coxiella burnetii. Microbes Infect. 11, 671-679. doi: 10.1016/j.micinf.2009.04.005

Smolková, K., Plecitá-Hlavatá, L., Bellance, N., Benard, G., Rossignol, R., and JeŽek, P. (2011). Waves of gene regulation suppress and then restore oxidative phosphorylation in cancer cells. Int. J. Biochem. Cell Biol. 43, 950-968. doi: 10.1016/j.biocel.2010.05.003

Somashekar, B. S., Amin, A. G., Rithner, C. D., Troudt, J., Basaraba, R., Izzo, A., et al. (2011). Metabolic profiling of lung granuloma in Mycobacterium tuberculosis infected guinea pigs: ex vivo ${ }^{1} \mathrm{H}$ magic angle spinning NMR studies. J. Proteome Res. 10, 4186-4195. doi: $10.1021 / p r 2003352$

Somashekar, B. S., Amin, A. G., Tripathi, P., MacKinnon, N., Rithner, C. D., Shanley, C. A., et al. (2012). Metabolomic signatures in guinea pigs infected with epidemic-associated W-Beijing strains of Mycobacterium tuberculosis. J. Proteome Res. 11, 4873-4884. doi: 10.1021/pr300345x

Sonje, M. B., Abram, M., Stenzel, W., and Deckert, M. (2010). Listeria monocytogenes (delta-actA mutant) infection in tumor necrosis factor receptor p55-deficient neonatal mice. Microb. Pathog. 49, 186-195. doi: 10.1016/j.micpath.2010.05.012

Stavru, F., Archambaud, C., and Cossart, P. (2011). Cell biology and immunology of Listeria monocytogenes infections: novel insights Immunol. Rev. 240, 160-184. doi: 10.1111/j.1600-065X.2010.00993.x

Stecher, B., Robbiani, R., Walker, A. W., Westendorf, A. M., Barthel, M., Kremer, M., et al. (2007). Salmonella enterica serovar typhimurium exploits inflammation to compete with the intestinal microbiota. PLoS Biol. 5, 2177-2189. doi: 10.1371/journal.pbio.0050244

Stephens, R. S. (2003). The cellular paradigm of chlamydial pathogenesis. Trends Microbiol. 11, 44-51. doi: 10.1016/S0966-842X(02)00011-2

Szaszák, M., Steven, P., Shima, K., Orzekowsky-Schröder, R., Hüttmann, G., König, I. R., et al. (2011). Fluorescence lifetime imaging unravels C. trachomatis metabolism and its crosstalk with the host cell. PLoS Pathog. 7:e1002108. doi: 10.1371/journal.ppat.1002108

Tabernero, L., Aricescu, A. R., Jones, E. Y., and Szedlacsek, S. E. (2008). Protein tyrosine phosphatases: structure-function relationships. FEBS J. 275, 867-882. doi: 10.1111/j.1742-4658.2008.06251.x

Tam, M. A., Rydström, A., Sundquist, M., and Wick, M. J. (2008). Early cellular responses to Salmonella infection: dendritic cells, monocytes, and more. Immunol. Rev. 225, 140-162. doi: 10.1111/j.1600065X.2008.00679.x

Thiennimitr, P., Winter, S. E., Winter, M. G., Xavier, M. N., Tolstikov, V., Huseby, D. L., et al. (2011). Intestinal inflammation allows Salmonella to use ethanolamine to compete with the microbiota. Proc. Natl. Acad. Sci. U.S.A. $108, \quad 17480-17485$. doi: 10.1073/pnas.1107857108

Tran Van Nhieu, G., and Arbibe, L. (2009). Genetic reprogramming of host cells by bacterial pathogens. F1000 Biol. Rep.1:80. doi: $10.3410 / \mathrm{B} 1-80$

Tung, S. M., Unal, C., Ley, A., Peña, C., Tunggal, B., Noegel, A. A. et al. (2010). Loss of Dictyostelium ATG9 results in a pleiotropic phenotype affecting growth, development, phagocytosis and clearance and replication of Legionella pneumophila. Cell. Microbiol. 12, 765-780. doi: 10.1111/j.1462-5822.2010.01432.x

Turner, J. R. (2000). Show me the pathway! Regulation of paracellular permeability by $\mathrm{Na}(+)$-glucose cotransport. Adv. Drug Deliv. Rev. 41, 265-281. doi: 10.1016/S0169409X(00)00046-6

Uchiya, K., and Nikai, T. (2004). Salmonella enterica serovar Typhimurium infection induces cyclooxygenase 2 expression in macrophages: involvement of Salmonella pathogenicity island 2 . Infect. Immun. 72, 6860-6869. doi: 10.1128/IAI.72.12.6860-6869.2004 van der Wel, N., Hava, D., Houben, D., Fluitsma, D., van Zon, M., 
Pierson, J., et al. (2007). M. tuberculosis and $M$. leprae translocate from the phagolysosome to the cytosol in myeloid cells. Cell 129, 1287-1298. doi: 10.1016/j.cell.2007. 05.059

van Eunen, K., Rossell, S., Bouwman, J., Westerhoff, H. V., and Bakker, B. M. (2011). Quantitative analysis of flux regulation through hierarchical regulation analysis. Methods Enzymol. 500, 571-595. doi: 10.1016/B978-012-385118-5.00027-X

Vinson, G. P. (2009). The adrenal cortex and life. Mol. Cell. Endocrinol. 300, 2-6. doi: 10.1016/j.mce.2008.09.008

Volpe, E., Cappelli, G., Grassi, M., Martino, A., Serafino, A., Colizzi, V., et al. (2006). Gene expression profiling of human macrophages at late time of infection with Mycobacterium tuberculosis. Immunology 118, 449-460.

Voth, D. E., and Heinzen, R. A. (2009). Coxiella type IV secretion and cellular microbiology. Curr. Opin. Microbiol. 12, 74-80. doi: 10.1016/j.mib.2008.11.005

Vousden, K. H., and Ryan, K. M. (2009). p53 and metabolism. Nat. Rev. Cancer 9, 691-700. doi: $10.1038 / \mathrm{nrc} 2715$

Wagner, M. (2009). Single-cell ecophysiology of microbes as revealed by Raman microspectroscopy or secondary ion mass spectrometry imaging. Annu. Rev. Microbiol. 63, 411-429. doi: 10.1146/annurev. micro.091208.073233

Wang, J. P., Rought, S. E., Corbeil, J., and Guiney, D. G. (2003). Gene expression profiling detects patterns of human macrophage responses following Mycobacterium tuberculosis infection. FEMS Immunol. Med. Microbiol. 39, 163-172. doi: 10.1016/S0928-8244 (03)00223-2

Wang, Y., Couture, O. P., Qu, L., Uthe, J. J., Bearson, S. M., Kuhar, D., et al. (2008). Analysis of porcine transcriptional response to Salmonella enterica serovar Choleraesuis suggests novel targets of NFkappaB are activated in the mesenteric lymph node. BMC Genomics 9:437. doi: 10.1186/1471-21649-437

Warburg, O. (1956). On respiratory impairment in cancer cells. Science 124, 269-270.

Weber, S. S., Ragaz, C., and Hilbi, H. (2009). Pathogen trafficking pathways and host phosphoinositide metabolism. Mol. Microbiol. 71, 1341-1352. doi: 10.1111/j.13652958.2009.06608.x

Wendler, W. M., Kremmer, E., Förster, R., and Winnacker, E. L. (1997). Identification of pirin, a novel highly conserved nuclear protein. J. Biol. Chem. 272, 8482-8489. doi: 10.1074/jbc.272.13.8482

Werth, N., Beerlage, C., Rosenberger, C., Yazdi, A. S., Edelmann, M., Amr, A., et al. (2010). Activation of hypoxia inducible factor 1 is a general phenomenon in infections with human pathogens. PLoS ONE 5:e11576. doi: 10.1371/journal.pone.0011576

Wieland, H., Ullrich, S., Lang, F., and Neumeister, B. (2005). Intracellular multiplication of Legionella pneumophila depends on host cell amino acid transporter SLC1A5. Mol.
Microbiol. 55, 1528-1537. doi: 10.1111/j.1365-2958.2005.04490.x

Winter, S. E., Thiennimitr, P., Winter, M. G., Butler, B. P., Huseby, D. L., Crawford, R. W., et al. (2010). Gut inflammation provides a respiratory electron acceptor for Salmonella. Nature 467, 426-429. doi: 10.1038/nature09415

Wise, D. R., DeBerardinis, R. J., Mancuso, A., Sayed, N., Zhang, X. Y., Pfeiffer, H. K., et al. (2008). Myc regulates a transcriptional program that stimulates mitochondrial glutaminolysis and leads to glutamine addiction. Proc. Natl. Acad. Sci. U.S.A. 105, 18782-18787. doi: 10.1073/pnas. 0810199105

Wu, S., Ye, Z., Liu, X., Zhao, Y., Xia, Y., Steiner, A., et al. (2010). Salmonella typhimurium infection increases p53 acetylation in intestinal epithelial cells. Am. J. Physiol. Gastrointest. Liver Physiol. 298, G784-G794. doi: 10.1152/ajpgi. 00526.2009

Wu, X., Lei, L., Gong, S., Chen, D., Flores, R., and Zhong, G. (2011). The chlamydial periplasmic stress response serine protease $\mathrm{cHtrA}$ is secreted into host cell cytosol. BMC Microbiol. 11:87. doi: 10.1186/14712180-11-87

Xiong, Y., and Guan, K. L. (2012). Mechanistic insights into the regulation of metabolic enzymes by acetylation. J. Cell Biol. 198, 155-164. doi: 10.1083/jcb.201202056

Zhang, W., Li, F., and Nie, L. (2010) Integrating multiple 'omics' analysis for microbial biology: application and methodologies.
Microbiology 156, 287-301. doi: 10.1099/mic.0.034793-0

Zhong, G., Fan, P., Ji, H., Dong, F., and Huang, Y. (2001). Identification of a chlamydial protease-like activity factor responsible for the degradation of host transcription factors. J. Exp. Med. 193, 935-942. doi: 10.1084/jem.193.8.935

Zou, T., Garifulin, O., Berland, R., and Boyartchuk, V. L. (2011). Listeria monocytogenes infection induces prosurvival metabolic signaling in macrophages. Infect. Immun. 79, 1526-1535. doi: 10.1128/IAI. 01195-10

Conflict of Interest Statement: The authors declare that the research was conducted in the absence of any commercial or financial relationships that could be construed as a potential conflict of interest.

Received: 30 April 2013; accepted: 11 June 2013; published online: 09 July 2013.

Citation: Eisenreich W, Heesemann J, Rudel T and Goebel W (2013) Metabolic host responses to infection by intracellular bacterial pathogens. Front. Cell. Infect. Microbiol. 3:24. doi: 10.3389/ fcimb.2013.00024

Copyright (C) 2013 Eisenreich, Heesemann, Rudel and Goebel. This is an open-access article distributed under the terms of the Creative Commons Attribution License, which permits use, distribution and reproduction in other forums, provided the original authors and source are credited and subject to any copyright notices concerning any third-party graphics etc. 